\title{
Spectral indicators as a tool to assess the moisture status of forest habitats
}

Adam Młynarczyk ( $\square$ adam.mlynarczyk@amu.edu.pl )

Adam Mickiewicz University in Poznań

Monika Konatowska

Poznań University of Life Sciences

Sławomir Królewicz

Adam Mickiewicz University in Poznań

Paweł Rutkowski

Poznań University of Life Sciences

Jan Piekarczyk

Adam Mickiewicz University in Poznań

\section{Research Article}

Keywords: Spectral indicators, forest habitats, NDVI, water, Sentinel-2

Posted Date: January 17th, 2022

DOI: https://doi.org/10.21203/rs.3.rs-1258644/v1

License: (c) (1) This work is licensed under a Creative Commons Attribution 4.0 International License.

Read Full License 


\section{Abstract}

Measurement of water content in forest habitats is considered essential in all ecological research on forests, climate change or forest management, but also in protection against floods, wildfires and soil erosion. In traditional forest habitat classification two systems of habitat conditions analysis are found: single factor or multifactor methods. Both labour-intensive and time-consuming, and therefore costly. Remote sensing methods provide a sound and low-cost alternative. The aim of the presented study was to find the relationship between the spectral indicators obtained from satellite images and the Forest Habitats Moisture Indexes used traditionally in the Polish forest habitats classification system, allowing their practical use in forest management and the protection of forest ecosystems, not only in Poland. The research area was Bory Tucholskie National Park, in which the results of habitat studies performed with the traditional approach were compared with the analysis of 191 spectral indicators calculated for Sentinel-2 image data. Normalized Difference Vegetation Index (NDVI) was considered to best reflect the moisture content in forest habitats, but also the trophic status, provided that spectral images from the full growing season, which in the study area cover the period from June to August, are taken into account. The results of the research also highlight the impact of water reservoirs on the humidity and trophicity of forest habitats, showing a decrease in the fertility of forest habitats with distance from the water reservoir.

\section{Introduction}

Forests play a key role in the Earth's water cycle $\mathrm{e}^{1,2}$ hence the measurement of water content in forest habitats is considered essential in all ecological research on forests, climate change or forest management, as well as against floods, fires and soil erosion. In traditional forest habitat classification, two systems for the analysis of habitat conditions are found: single factor or multifactor methods ${ }^{3}$. Single factor methods rely on one factor to describe a forest site, such as soil or climate, whereas multifactor methods are based on interrelationships between climate, physiography, soil and vegetation 4 . An example of the use of the single factor method can be digital site classification maps used in Germany, created by the State Forest Administration, containing information on the thickness of the soil profile, grain size, density and organic matter content in the soil, as well as on climatological and topographic factors (exhibition and slope), on the basis of which a quantitative description of the water regime of soils can be obtained ${ }^{5}$. The maps show the spatial distribution of 9 soil moisture classes, from extremely moist to extremely dry. The Multifactor method is used, among others, in Poland ${ }^{6,7}$. It is based on the recognition of the features of the tree stand, plant communities and soil properties and combining these elements into one abstract unit, which is the forest habitat type (FHT). In total, there are 38 such units in Poland, divided depending on their geographic location into lowland (15), highland (8) and mountain (15) units. The basic element of the assessment of forest soils is their trophic and moisture differentiation. Due to the trophic diversity of forest habitats, there are, in Poland: coniferous forests, conifer-dominated mixed forests, deciduous-dominated mixed forests and deciduous forests. Due to the humidity diversity, the forest habitat types are divided into dry, mesic, moist and swampy. The 
combination of trophic and moisture features gives the name of FHT. For example, if trophically a forest belongs to the group of conifer-dominated mixed forests and in terms of humidity to mesic types, then the forest habitat type is called mesic conifer-dominated mixed forest.

The criteria for the differentiation of forest habitat types into moisture groups are based on the assessment of two basic types of water: habitats depend on precipitation and habitats depend on groundwater. Forest Habitats Moisture Index (FHMI) based on groundwater (groundwater level), is assessed depending on the depth of water in the soil. Habitats with water on the ground surface or at the depth of 0-20 cm are described as "g1" FHMI (Fig. 1). Habitats with groundwater in the range of 20-50 cm as g2, in the range of $50-80 \mathrm{~cm}$ as g3, in the range of $80-180 \mathrm{~cm}$ as $\mathrm{g} 4$ and in the range of $180-250 \mathrm{~cm}$ as g5. When the water is below $250 \mathrm{~cm}$, the habitat is classified as g6, and when the habitats are additionally covered with the poorest forms of pine forests in Poland, so called "Dry Forest", they are classified as $\mathrm{g} 7^{6,7}$.

Studies that analyze the FHMI in this way are carried out in Poland on all lands managed by the State Forests National Forest Holding, covering approx. $23 \%$ of the country's land area and approx. $77 \%$ of the Polish total forest area ${ }^{8}$, with an accuracy of 1 research plot per 4-12 ha, depending on the diversity of the terrain, repeating them every 30 years. This method of assessing the suitability of forest soils in terms of forest management is quite precise, but time-consuming and costly. Therefore, faster and cheaper methods are sought, including those based on remote sensing ${ }^{9-12}$.

In numerous publications on the use of remote sensing methods, soil moisture is analyzed mainly in its surface layers ${ }^{13-16}$, while the general water supply is important for the development of the forest, available both within the reach of tree roots and related to precipitation and air humidity. Therefore, it was decided to look for indirect methods in assessing the FHMI, based on plant indicators (NDVI and others), assuming that remote sensing methods can indicate such a condition of forest vegetation that reflects the diverse moisture conditions of forest habitats.

Remote sensing methods based on the registration of spectral reflectance have been used for several decades and, similarly to terrestrial techniques, are developed mainly for the needs of agriculture ${ }^{17-22}$. More and more often remote sensing methods are also used in forestry, but mainly in terms of assessing the health condition of the forest, as well as abiotic threats, such as fires ${ }^{23}$ or droughts ${ }^{24}$ and biotic ones, such as insect outbreaks ${ }^{25}$.

Remote sensing vegetation studies are based on near and far infrared radiation as well as other ranges of radiation reflected and absorbed by plants ${ }^{26-29}$. Remote sensing uses both aerial, ground and satellite imagery. Despite dynamically developing measurement techniques ${ }^{30-36}$ in attempts to study the FHMI on the basis of remote sensing, the obstacle is what is the essence of the forest - the plant cover ${ }^{37}$. So far, a barrier to the use of available remote measurement methods is also the low resolution of the image products of such studies (coarse spatial resolution from 25 to $50 \mathrm{~km}$ ), reaching tens of kilometers ${ }^{16,38}$, which is not sufficient for the needs of users which may be foresters, farmers or plant growers. 
Research on the possibility of using remote sensing in estimating the moisture content of forest soils is carried out in many places around the world. Nijland et al. ${ }^{39}$ investigated the relationship between soil moisture and site productivity of four types of Canadian forests (CD: conifer-dominated; MX: mixed conifer-deciduous; DU: deciduous dominated with conifer understory; DD: deciduous dominated) and NDVI maximum pre-harvest values from Landsat images. The authors showed that the relationship between NDVI and the humidity of the habitat was negative and the relationship with the depth of groundwater was positive, what the authors explained by the large diversity of stand types occurring in different habitats. A stronger correlation between productivity and moisture content was observed in coniferous and mixed stands compared to two types of forests with a predominance of deciduousdominated forest types. Moreover, the habitats of mixed and coniferous forests were characterized by greater diversity in both humidity and productivity than habitats with a predominance of deciduous trees.

In forests of the German Rhineland-Palatinate state Dotzler et al. ${ }^{40}$ conducted research on detecting tree water stress responses in deciduous forests [dominated by beech (Fagus sylvatica) and sessile and pedunculate oaks (Quercus petraea and $Q$. robur)] using hyperspectral aerial images. The spectral index PRI (Photochemical Reflectance Index) calculated on their basis showed differences between habitats caused by drought and depending on soil moisture conditions. Based on the analysis of the identified divisions on PRI maps, the authors proposed to combine some of the 9 classes, thanks to which, finally, 3-4 important classes were obtained with information on the availability of soil water in vast forest areas.

Coniferous species dominate in Polish forests $(68.2 \%$ of the area of Polish forests, including pine (Pinus sylvestris), which covers $58 \%$ of all forest areas, $60.1 \%$ of the area of the State Forests and $54.5 \%$ of private forests ${ }^{8}$. The dominant type of forest soils in Poland are rusty soils ${ }^{41}$. For forests in Poland, the main source of water are atmospheric precipitation and air humidity ${ }^{42}$.

The aim of this study was to find the relationship between the spectral indices obtained from satellite images and the moisture state of forest habitats, allowing for their practical use in forest management and the protection of forest ecosystems.

\section{Materials \& Methods}

\subsection{Research area}

The research area is the Bory Tucholskie National Park (BTNP), considered by authors as a representative area for Polish forest conditions. located in northern part of Poland (Fig. 2), in formerly glaciated areas with a varied topography, cut by the gutters of glacial lakes. Over $90 \%$ of the park area is covered by suboceanic pine forests (Leucobryo-Pinetum plant association) ${ }^{43}$. The dominant type of soil is rusty soils, formed mainly of outwash sands. The extreme points of the test area are marked by geographical coordinates: west $17^{\circ} 30^{\prime} 08.3^{\prime \prime} \mathrm{E}, 53^{\circ} 48^{\prime} 54.8^{\prime \prime} \mathrm{N}$; north $17^{\circ} 32^{\prime} 30.9^{\prime \prime} \mathrm{E}, 53^{\circ} 51^{\prime} 23.7^{\prime \prime} \mathrm{N}$; east $17^{\circ} 37^{\prime} 06.3^{\prime \prime} \mathrm{E}$, $53^{\circ} 47^{\prime} 58.6^{\prime \prime} \mathrm{N}$; south $17^{\circ} 34^{\prime} 51.6^{\prime \prime} \mathrm{E}, 53^{\circ} 46^{\prime} 15.8^{\prime \prime} \mathrm{N}$.

\subsection{Satellite data}


The search and download of Sentinel-2 (A, B) images of the European Space Agency (ESA) was made from the Polish data repository of the Copernicus program (https://www.copernicus.eu/en), Sat4Envi (https://sat4envi.imgw.pl/) managed by the Polish Institute of Meteorology and Water Management (IMGW-PIB). The characteristics of the Multispectral Instrument (MSI) sensor on S2A and S2B platforms are available on the ESA website (https://sentinels.copernicus.eu/web/sentinel/user-guides/sentinel-2msi). Data from the level of the product Level L2A were used for the analysis. It is a product that was created as a result of geometric correction taking into account the influence of topography on the image and radiometric correction of radiation changes in the atmosphere. The BTNP is located in the area of one section (Tile) (Fig. 2C) designated T33UXV (UTM). The time range of image search was limited to three years, from 01 January 2018 to 31 December 2020, and the criterion of cloud cover covering the section was less than or equal to $70 \%$. Such a large value of the cloudiness parameter was assumed, because the Park covers only $0.38 \%$ of the section area (whole Park area $46.13 \mathrm{~km}^{2}$ / Tile area $100 \times 100$ $\mathrm{km}=10000 \mathrm{~km}^{2}$ ). Then, the acquired images were cropped to a regular fragment including BTNP using a geometric object in SHP format. Cropped images were done in Microimages TNTmips. In the next step, images with no cloud cover in the research area were selected. The initial image classification layer SCL (Scene Classification Layer) was used for this, by checking whether there are values on this layer corresponding to clouds and their shadows as well as snow cover. In the SCL classification raster, such surface categories are marked with the following values: shadows - 3 , clouds with low probability - 7 , medium - 8 , high - 9 , cirrus clouds -10 , snow -11 . Finally, the criterion eliminating the display term defined as follows was applied: if there were clouds of medium (8) and high probability (9) in the polygon area and if the number of such pixels was greater than 50 in the image, then such an image was removed; if the number was lower than 50 pixels, the spatial distribution of clouds and over which polygons they are located were visually checked. In the case of high scattering of individual pixels, the term of imaging was included in the set of analysed images.

Geometric data on the ranges of forest habitat units (Fig. 3), available in the SHP format, together with the database in the following formats: .prj, .sbn, .sbx, .shx, were obtained from the website of the Bory Tucholskie National Park Geoportal (http://gis.pnbt.com.pl/). Due to the spatial resolution of satellite images $(10-60 \mathrm{~m})$, units with an area smaller than 1 ha were excluded from the analysis, which also corresponds to the methodology of identifying habitat conditions using the traditional terrestrial method ${ }^{7}$.

In the next step, for each Sentinel-2 data recording date, the average values, from pixels DNs corresponds to reflectance multiply by 10000 , for all spectral bands (except for band number 9 , which is not present in the L2A product) were calculated for forest habitat units (polygons). Calculations were made in Microimages TNTmips v. 2021. The principle of calculating the mean of pixels values entirely located within the area of the forest unit was adopted. Therefore, border pixels lying under the boundaries of forest habitat units were rejected from calculation.

In the next stage, for each image recording date, on the basis of the average DN values of the pixels of photos from different spectral channels of the MSI Sentinel-2A sensor within the polygons of individual FHMIs, 249 vegetation indices were calculated, the formulas of which are stored in the "Index Database" 
(https://www.indexdatabase.de/) ${ }^{44}$. Ultimately, after the selection and analysis of the formulas, 191 indicators were selected for the calculation. A list of all selected indices and their formulas (via a link to the appropriate page in the "Index Database") is included in Supplementary Materials.

All further calculations were performed with the Excel spreadsheet software from Microsoft. For all polygons belonging to the same humidity category, for a given image recording date, the mean value of the index $\left(\mathrm{M}_{\text {in Tgi }}\right)$ and the standard deviation therefrom $\left(\mathrm{SD}_{\text {inTgi }}\right)$ were calculated. Then, the relationship between the mean values of the indices calculated for one term and the FHMIs ranked descendingly from the wettest (g1) to the driest (g7) was investigated using the linear regression method.

Then, using the linear regression method, the values of the coefficient of determination $\mathrm{R}^{2}{ }_{\text {inTgi }}$ were calculated (function r.square() in Excel). In addition to the value of the coefficient of determination, the equation of a straight line describing this relationship was obtained. The normalization of the slope by calculating the new Slope $_{\mathrm{Lg} 1 \mathrm{Tg} 7}$ coefficient was performed using the following rules:

1) if the slope of the line was positive, the normalization was made according to the formula:

SlopeL $\mathrm{g}_{1 \mathrm{Tg}}=\left(\mathrm{M}_{\mathrm{inTg} 1}+\mathrm{SD}_{\mathrm{inTg} 1}+1\right) /\left(\mathrm{M}_{\mathrm{inTg}}-\mathrm{SD}_{\mathrm{inTg}}+1\right)(1)$

2) if the slope of the line was negative or equal to zero, then the normalization was made according to the formula:

SlopeL $\mathrm{g} 1 \mathrm{Tg}_{7}=\left(\mathrm{M}_{\mathrm{inTg} 7}-\mathrm{SD}_{\mathrm{inTg} 7}+1\right) /\left(\mathrm{M}_{\mathrm{inTg} 1}+\mathrm{SD}_{\mathrm{inTg} 1}+1\right)(2)$

Another element of the assessment of the strength of the relationship, concerning the assessment of the size of the standard deviations of the indicators in terms of moisture content (at a given time), was the calculation of the sum of the quotients of the standard deviations and the average values of the indicator of all humidity categories $\left(\right.$ Suml $_{\mathrm{inT}}$ ) according to the following formula:

SumRatio $_{\text {inT }}=\sum\left(\mathrm{SD}_{\mathrm{inTg} 1} / \mathrm{M}_{\mathrm{inTg} 1}+\ldots+\mathrm{SD}_{\mathrm{inTg} 7} / \mathrm{M}_{\mathrm{inTg}}\right)$

For an ideal situation for the relationship between the degree of moisture and the spectral index, the standard deviations should be close to zero and therefore the proposed sum would also be zero.

The usefulness of the analyzed indices was assessed on the basis of a synthetic measure defined according to the following formula:

$E_{\text {inTg }}=R^{2}{ }_{\text {inTgi }}$ * $\left(1-\right.$ SlopeL $\left._{\text {g1Tg7 }}\right)$ * SumRatio ${ }_{\text {inT }}(4)$

\subsection{Meteorological data}

Meteorological data on the course of monthly precipitation totals and long-term averages for the nearest measuring station in Chojnice (location of the meteorological station $171.9 \mathrm{~m}$ above sea level, 
geographical coordinates: $17^{\circ} 31^{\prime} 57^{\prime \prime} \mathrm{E}, 53^{\circ} 42^{\prime} 55^{\prime \prime} \mathrm{N}$ ) were downloaded from the data archive (https://danepubliczne.imgw.pl/) run by the Institute of Meteorology and Water Management (IMGW-PIB).

\section{Results}

The weather conditions in a given growing season, and especially the amount of rainfall, has a significant influence on the forest habitats moisture. Their amount in the earlier season is also of very important, as they can affect the condition of trees. During the study period only in 2018 the average amount of precipitation was slightly lower (by $33 \mathrm{~mm}$ ) than the multiannual average (Fig. 4), while significantly higher precipitation (by $266 \mathrm{~mm}$ ) than the average for the multiannual period was observed in 2017. The highest precipitation in the second half of the season, thanks to which the water retention reserves for the next season were the highest, occurred in the following years: 2017 (548 mm), 2019 (362.5 mm), $2018(287 \mathrm{~mm})$ and $2020(261.7 \mathrm{~mm})$.

The soil cover of the Bory Tucholskie National Park shows relatively little typological differentiation, which results from the relatively homogeneous geological structure of the substrate. The parent materials of the soils are mainly sandy glacial sediments of the Vistula glaciation and the Holocene, most often loose sands, in total covering $98.6 \%$ of the Park's area. With the dominance of sandy parent materials with low water retention (total loose sands or sands lying on various substrates), with a relatively short time of soil development and under temperate climate conditions, forests are natural vegetation under which mainly podzolic-rusty soils have developed, and less typical podzolic or brunic rusty soils. These three soil subtypes cover a total of 3706 ha and constitute $80 \%$ of the Park's area. Table 1 shows the FHMls (g1-g7) and the humidity groups distinguished within the forest habitat types.

Table 1

Groundwater levels occurring in the Forest Habitat Types area of the Bory Tucholskie National Park

\begin{tabular}{|lllll|}
\hline FHMI & Moisture group of habitats & Groundwater table $[\mathrm{m}]$ & Number of sites & $\begin{array}{l}\text { Area } \\
\text { [ha] }\end{array}$ \\
\hline g1 & Swampy & $0.0-0.2$ & 13 & 37.89 \\
\hline g2 & Swampy & $0.2-0.5$ & 70 & 121.439 \\
\hline g3 & Moist & $0.5-0.8$ & 73 & 190.429 \\
\hline g4 & Moist & $0.8-1.8$ & 74 & 118.709 \\
\hline g5 & Mesic & Below 1.8 & 58 & 170.64 \\
\hline g6 & Mesic & Below 2.5 & 625 & 3653.34 \\
\hline g7 & Dry & Below 2.5 & 10 & 17.14 \\
\hline Total & & & 923 & 4309.59 \\
\hline
\end{tabular}


In the vector layer of the Park's habitats, 923 contours were distinguished, covering the surfaces of forest habitats with seven degrees of FHMIs.

Within the g1 FHMI, there were only peat soils, mostly fertile peats. To the g2 and g3 FHMls, rised bogs and fen peat soils predominated. To the g4 FHMI, groundwater glayed soils had the greatest share, to the g5 FHMI typical podzolic soils, to the g6 FHMI rusty podzolic soils, and to the $\mathrm{g} 7 \mathrm{FHMI}$ arenosols.

Figure 5 shows the spectral characteristics of habitats with different levels of soil moisture obtained from the Sentinel-2 image recorded on 08 June 2021. Based on the level of the spectral curves (reflectance) in the near infrared range (channel $8 \mathrm{~A}$ ), three groups of habitats with different $\mathrm{FHMI}$ can be distinguished: (i) wet - g1, with mainly deciduous trees, (ii) strongly moist - g2, very moist - g3 and moist - g4 covered with mixed forest and (iii) moist-mesic - g5, mesic - g6 and dry - g7 covered with pine forests. The driest habitats were distinguished by higher reflection in the visible range, especially in the red channel and in the range of short-wave infrared SWIR in channel 12.

Among the analyzed vegetation indices, NDVI turned out to be the most strongly correlated with the FHMI, during the full growing season, which in Poland falls on the period from June to August. Figures 6-11 show the differentiation of the values of the determination coefficients $\left(R^{2}\right)$, calculated for the relationship between the FHMIs and the average values of the NDVI index obtained from satellite images recorded in 2018, 2019 and 2020. As the g7 FHMI significantly differed from the others in each of the research periods, the analysis of $R^{2}$ in the same years was also compiled, excluding the $\mathrm{g} 7$ degree, which resulted in an increase in $\mathrm{R}^{2}$, from the average value for 2018-2020 equal 0.73 to the value of 0.89 . When analyzing the data on the graphs, it should be noted that the degrees of moisture content correlated with the NDVI index do not represent a specific depth of groundwater, but the ranges in which the groundwater level fluctuates during the growing season (Fig. 1). It should also be noted that the boundaries of the groundwater level depth ranges are tangent for the adjacent FHMIs (Fig. 1). The NDVI values are also in such a sequence, showing similar values for the neighbouring moisture indexes and clearly differentiate between the groups of moisture in forest habitats: swampy (g1-g3), moist (g3-g4), mesic (g5-g6), dry (g7), as shown in Fig. 6 . Figure 6 also distinguish indexes g6 and g7, assuming the lowest NDVI values and representing soils with no groundwater at a depth of up to $250 \mathrm{~cm}$.

When selecting the dates for the data analysis in the years 2018-2020, used to prepare the charts presented in Figs. 6-11, an attempt was made to select the most similar dates in individual years. In 2018 and 2019, for the presented examples it was June 20. In 2020, due to weather conditions, good-quality satellite photos were not obtained until August 8 . Hence the discrepancy in the dates.

Figures 12-23 show, for example dates, data with the highest indexes positions in the ranking: BGI (Simple Ratio 450/550 Blue green pigment index), DSWI-4 (Simple Ratio 550/680 Disease-Water Stress Index 4, EVI (Enhanced Vegetation Index), SR520/670 (Simple Ratio 520/670), taking into account all the calculated indicators. A ranking of all indicators, ranked from the best to the worst with the FHMIs, and 
the remaining graphs illustrating all the results calculated for the $\mathrm{R}^{2}$ coefficient, can be found in Supplementary Materials.

Figures 24-32 also show changes in the relationship between NDVI and moisture levels at different times in the same year (2020). This analysis illustratively shows the relationship between NDVI, the FHMIs and the seasons of the year. Lack of data for g1-g3 FHMls and low NDVI value for g4 FHMI results from the trophic nature of wet habitats, which, as generally more fertile, have a greater share of deciduous species, in winter and early spring without of leaves in Poland, while habitats g5 and g6 mostly, and the g7 habitats are fully associated with pine, which the assimilation apparatus maintains throughout the year. Based on the graphs shown in Figs. 24-32 it can be assumed that in spring and autumn the trend line is ascending (no leaves on deciduous trees, presence of pine needles), in summer the trend line is descending (deciduous trees have more chlorophyll, with full foliage). In winter, when the plants are dormant, the NDVI values are relatively low (below 0.6 ) for obvious reasons.

As it has been shown and as mentioned earlier, the NDVI index correlates with the FHMIs in the summer and this period should be taken into account in Central Europe when determining the degree of moisture in forest habitats on the basis of NDVI.

In order to illustrate the relationship between NDVI and FHMIs, the images of site maps made with the traditional method of soil pits were also compared with the image of the same area differentiated due to the NDVI values, grouping swampy (g1-g3 FHMIs), moist (g4) and moist-mesic (g5) and mesic habitats (g6). The imaging results are presented in Fig. 33.

\section{Discussion}

The presented data indicate a relationship between NDVI and the Forest Habitat Moisture Indexes, what is wider than relationship between NDVI and soil moisture presented by Huete ${ }^{45}$ in the results of his work as early as 1988. However, the author considered this relationship between NDVI and soil condition as a kind of obstacle in the NDVI analysis, paid attention to dynamic changes in the condition of soils related to their moisture content. The conducted research indicates that it is rather an advantage in understanding the spectral properties of soils and their interaction with vegetation and hydrological conditions.

Based on the conducted research, it is considered that the correct way to use the NDVI index to assess the FHMls should be to combine the degree of moisture into the following humidity groups: swampy, moist, mesic and dry (Fig. 6). Such a connection may eliminate some discrepancies between the data obtained from the traditional identification of habitat conditions and the data obtained from satellite images. In the traditional method used in Poland ${ }^{7}$, the FHMIs are determined according to the current water level in the ground on the date of the research. The remote sensing method allows to capture differences in the moisture status of habitats in a long-term perspective. It should also be noted that the traditional method is based on the results of measuring groundwater at the test point, which is a soil pit representing an area of one to more hectares. Within the distinguished habitat contour, however, there may be differences in 
the moisture conditions, which is illustrated by satellite images with a resolution of $10 \times 10 \mathrm{~m}$. The obtained results from the analysis of remote sensing data may also reflect not only the influence of groundwater, but also the effect of other water sources, to which plants react, e.g. related to differences in air humidity. For the area where the research was conducted, abundant in lakes, it may be of significant importance, as pointed out by Rutkowski ${ }^{42}$ when analyzing the diversity of humidity conditions in forest habitats for the area of Wielkopolska Region (central-western part of Poland). On this basis, it can be concluded that climatic conditions are the key factor in the habitat of terrestrial ecosystems, which is also confirmed by the results of Rutkowski's ${ }^{46}$ research. In this context, satellite images, reflecting the comprehensive impact of waters of various origins on forest ecosystems, may be a much more sensitive tool for assessing the moisture diversity of forest habitats than traditional methods based mainly on the description and assessment of soil diversity.

It should be noted, however, that apart from NDVI, relatively high compliance with the humidity conditions was also shown by the following indicators: EVI (Fig. 34), SAVI (Soil Adjusted Vegetation Index - Fig. 35), SR520/670 (Fig. 36) and OSAVI (Optimized Soil Adjusted Vegetation Index - Fig. 37). These indicators also reflect well areas with little vegetation cover, such as forest roads or stands up to 15 years old (for example, the area marked in Figures B with the letter "b".

It should be noted that the concept of "Forest Habitat Moisture Index" used in Poland does not only mean the presence of groundwater at a specific depth. Therefore, it is not possible to unequivocally state its presence in soil on the basis of the presented indicators. The concept of "FHMIs" reflects the total impact of water available from various sources on the forest ecosystem, with traditional, terrestrial measurement methods often difficult to measure. With the dominance of sandy deposits in forest soils in Poland, where groundwater is generally below the root zone of trees, precipitation and water contained in moist air masses can be considered the main source of water. The impact of atmospheric precipitation on the forest is reflected in research publications ${ }^{47-49}$, while the impact of air humidity related to water reservoirs on the development of forest ecosystems is poorly described, and the data collected in this study suggest that it is important. This is reflected, inter alia, in Fig. 38, where the trophic system of forest habitats of the BTNP fragment was compared with the image obtained on the basis of the NDVI index. Figure 38B clearly shows the zone of more fertile habitats (red), concentrated on the edges of the lakes and the declining fertility of the habitats to the east from the largest lake visible in the figure. It should be added that westerly winds prevail in Poland, which means that humid air masses from the lake move mainly to the east, and this is also the habitat fertility gradient shown in Figures 38A and 38B. Although there is also a wide zone of more fertile habitats to the west of the lake, it is associated with the rivers that flow into the lake in these places. In contrast, to the east of the lake, the habitat fertility gradient can be attributed to air humidity, which decreases with distance from the lake. It should also be added that, as indicated in Figs. 38A and 38B, the habitat fertility gradient change zone is associated with the same type of soil (rusty soils), which, depending on the vegetation cover, can be differentiated into podzolic rusty (RDb), typical rusty (RDw) and brunic rusty (RDbr) soils - Fig. 39. 


\section{Conclusions}

Out of 191 analyzed vegetation indices, the NDVI index is useful to assess the degree of moisture in forest habitats. According to the conducted research, the condition for using the NDVI to assess the diversity of forests in terms of moisture content is to assume the full growing season for the indicator period, which in the conditions of central Europe falls in the period from June to August. For the four distinguished humidity groups: swampy habitats (g1-g3 Forest Habitat Moisture Indexes analyzed in the study), moist (g3-g4), mesic (g5-g6) and dry (g7), the best reflection of the humidity conditions in the three-year research period was obtained for the images of June 2018 and 2019 and August 2020. The difference in months results from the weather conditions related to cloudiness, and thus the availability of data from satellite images, but it can be assumed that the entire period, from June to August, is important.

The usefulness of EVI, SAVI and SR520/670 indicators has also been demonstrated, but using them to assess the moisture status of forest habitats limits their responses to areas with little or no forest coverage (e.g. stands up to 15 years old).

The obtained results also indicate the fertility gradient of forest habitats related to the vicinity of water reservoirs. It has been shown that the fertility of habitats decreases with distance from the water reservoir.

The presented research results could be implemented in forestry practice, which should significantly reduce the costs of identifying the diversity of forest habitats. The usefulness of the obtained results may, for example, refer to the determination of the boundaries of habitat units, which, based on the NDVI index, are clearly visible, and their accuracy, related to the resolution of satellite images on which the research was conducted $(10 \times 10 \mathrm{~m})$, is completely sufficient for the needs of forestry practice.

The results of the research can also be used to monitor the forest with regard to possible changes in the trophicity of habitats, which should help to protect forest ecosystems in the conditions of changing water resources, as a result of the impact of natural and anthropogenic factors.

\section{Declarations}

\section{Funding Information}

The research was financed from the project GEO-INTER-APLIKACJE nr POWR.03.02.00-00-I027/17. The project is co-financed by the European Uniom from the European Social Fund underground the Operation Program Knowledge Education Development.

\section{Author Contributions}

AM, JP, PR: conceptualization and methodology; AM: investigation; AM, SK: formal analysis; AM, MK: visualization; AM, MK, SK, PR, JP: writing original draft, review and editing. AM, JP: funding acquisition; 
validation

\section{Conflict of Interest and other Ethics Statements.}

Conflict of interest: The authors declare that they have no conflict of interest.

Ethics Statements: This article does not contain any studies involving human participants or animals performed by any of the authors.

\section{References}

1. Ellison, D. Forests and Water. Background Analytical Study, 2. United Nations Forum on Forests (2018).

2. Ellison, D. et al. Trees, forests and water: Cool insights for a hot world. Global Environmental Change, 43, 51-61 (2017).

3. Savill, P.S. Land classifcation for plantation forestry. Irish Forestry 40 (2), 78-91 (1983).

4. Farrelly, N., Fealy, R.M. \& Radford, T. The use of site factors and site classification methods for the assessment of site quality and forest productivity in Ireland. Irish Forestry 66 (2009).

5. Gauer, J., Feger, K.-H. \& Schwärzel, K. Erfassung und Bewertung des Wasserhaushalts von Waldstandorten in der forstlichen Standortskartierung: Gegenwärtiger Stand und künftige Anforderungen. Waldökologie, Landschaftsforschung und Naturschutz 12, 7-16 (2011).

6. Zielony, R. et al. Siedliskowe podstawy hodowli lasu. Załącznik do Zasad hodowli lasu. (Habitat basics of silviculture. Annex to the Principles of Silviculture). Warszawa, 1-264 (2004).

7. Święcicki, Z. (ed.) Instrukcja urządzania lasu, część 2: Instrukcja wyróżniania i kartowania w Lasach Państwowych typów siedliskowych lasu oraz zbiorowisk roślinnych. (Instruction of forest management, part 2: Instruction for distinguishing and mapping forest habitat types and plant communities in the State Forests) CILP, Warszawa (2012).

8. Zajączkowski, G. et al. Raport o stanie lasów w Polsce (Report on the state of forests in Poland) 2019. CILP, Warszawa (2020).

9. Albergel, C. et al. Evaluation of remotely sensed and modelled soil moisture products using global ground-based in situ observations. Remote Sens. Environ. 118, 215-226 (2012).

10. Kędzior, M. \& Zawadzki, J. Comparative study of soil moisture estimations from SMOS satellite mission, GLDAS database, and cosmic-ray neutrons measurements at COSMOS station in eastern Poland. Geoderma 283, 21-31 (2016).

11. Babaeian, E. et al. Ground, proximal, and satellite remote sensing of soil moisture. Rev. Geophys. 57, 530-616 (2019).

12. Sabaghy, S. et al. Comprehensive analysis of alternative downscaled soil moisture products. Remote Sens. Environ. 239, 111586 (2020). 
13. Polcher, J. et al. Comparing surface-soil moisture from the SMOS mission and the ORCHIDEE landsurface model over the Iberian Peninsula. Remote Sens. Environ. 174, 69-81 (2016).

14. Pinnington, E. et al. Improving soil moisture prediction of a high-resolution land surface model by parameterising pedotransfer functions through assimilation of SMAP satellite data. Hydrol. Earth Syst. Sci. Discuss. 25, 1617-1641 (2021).

15. Shellito, P.J. et al. Assessing the impact of soil layer depth specification on the observability of modeled soil moisture and brightness temperature. J. Hydrometeorol. 21, 2041-2060 (2020).

16. Peng, J. et al. Estimation and evaluation of high-resolution soil moisture from merged model and Earth observation data in the Great Britain. Remote Sensing of Environment 264, 112610 (2021).

17. Leamer, R.W., Noriega, J.R. \& Wiegand, C.L. Seasonal changes in reflectance of two wheat cultivars. Agronomy Journal, 70: 113-118 (1978).

18. O'Neill, P.E. et al. Effects of corn stalk orientation and water content on passive microwave sensing of soil moisture. Remote Sensing of Environment, 16, 55-67 (1984).

19. Ridao, E., Conde, J.R. \& Minguez, M.I. Estimating fAPAR from nine vegetation indices for irrigated and nonirrigated faba bean and semileafless pea canopies. Remote Sensing of Environment, 66, 87-100 (1998).

20. Vaesen, K., Gilliams, S., Nackaerts, K. \& Coppin, P. Ground-measured spectral signatures as indicators of ground cover and leaf area index: the case of paddy rice. Field Crops Research., 69, 13-25 (2001).

21. Piekarczyk, J. Temporal variation of the winter rape crop spectral characteristics. Int. Agrophysics, 15, 101-107 (2001).

22. Piekarczyk, J., Wójtowicz, M. \& Wójtowicz, A. Wpływ nawożenia azotowego i odmian na charakterystyki spektralne łanu rzepaku ozimego (Influence of nitrogen fertilisation and varieties on spectral characteristic of oilseed rape crop). Rośliny oleiste, 25, 281-291 (2004).

23. Gibson, R., Danaher, T., Hehir, W. \& Collins, L. A remote sensing approach to mapping fire severity in south-eastern Australia using sentinel 2 and random forest. Remote Sensing of Environment, 240, 111702. https://doi.org/10.1016/j.rse.2020.111702 (2020).

24. Asner, G.P. \& Alencar, A. Drought impacts on the Amazon Forest: the remote sensing perspective. New Phytologist 569-578. https://doi.org/10.1111/j.1469-8137.2010.03310.x (2010).

25. Fraser, R.H. \& Latifovic, R. Mapping insect-induced tree defoliation and mortality using coarse spatial resolution satellite imagery. Int. J. Remote Sens. 26, 193-200.

https://doi.org/10.1080/01431160410001716923 (2005).

26. Jones, H.G. \& Vaughan, R.A. Remote sensing of vegetation: principles, techniques, and applications. Oxford, Oxford University Press (2010).

27. Campbell, J.B. \& Wynne, R.H. Introduction to remote sensing. Fifth edition. New York, USA: Guilford Press (2011).

28. Wiśniewska, E. Wprowadzenie do analiz teledetekcyjnych obszarów leśnych. (Introduction to remote sensing analyzes of forest areas) In: Okła K. (Ed.), Geomatyka w Lasach Państwowych. Cz. 2. 
Poradnik praktyczny (Geomatics in the State Forests. Part 2. A practical guidebook). Warszawa: CILP, 152-167 (2013).

29. Czyż, P., Kowalik, A. \& Rutkowski, P. Application of Landsat satellite images for research on changes of vegetation conditions in the "Bagno Chlebowo" Natura 2000 site. Acta Sci. Pol. Silv. Colendar. Ratio Ind. Lignar., 15(3), 145-160. https://doi.org/10.17306/J. AFW.2016.3.17 (2016).

30. Dorigo, W.A. et al. Evaluation of the ESA CCI soil moisture product using ground-based observations, Remote Sens. Environ., 162, 380-395 (2015).

31. Montzka, C. et al. Validation of spaceborne and modelled surface soil moisture products with cosmic-ray neutron probes, Remote Sens., vol. 9, no. 2, Art. no. 103 (2017).

32. El Hajj, M. et al. Evaluation of SMOS, SMAP, ASCAT and Sentinel-1 soil moisture products at sites in Southwestern France, Remote Sens., vol. 10, no. 4, Art. no. 569 (2018).

33. Al-Yaari, A. et al. 2019. Assessment and inter-comparison of recently developed/reprocessed microwave satellite soil moisture products using ISMN ground-based measurements. Remote Sens. Environ. 224, 289-303.

34. Tian, J. \& Song, S. Application of cosmic-ray neutron sensing to monitor soil water content in agroecosystem in North China Plain, in Proc. IGARSS IEEE Int. Geosci. Remote Sens. Symp., pp. 7053-7056 (2019).

35. Gruber, A. et al. Validation practices for satellite soil moisture retrievals: What are (the) errors?, Remote Sens. Environ., vol. 244, Art. no. 111806 (2020).

36. Carranza, C., Nolet, C., Pezij M. \& van der Ploeg, M. Root zone soil moisture estimation with Random Forest. Journal of Hydrology, 593,125840 (2021).

37. Beale, J., Waine, T., Evans, J. \& Corstanje, R. A Method to Assess the Performance of SAR-Derived Surface Soil Moisture Products. IEEE Journal of Selected Topics in Applied Earth Observations and Remote Sensing, Vol. 14, (2021).

38. Qu, Y. et al. Inter-comparison of several soil moisture downscaling methods over the Qinghai-Tibet Plateau, China. Journal of Hydrology, 592, ISSN 0022-1694, https://doi.org/10.1016/j.jhydrol.2020.125616 (2021).

39. Nijland, W. et al. Remote sensing proxies of productivity and moisture predict forest stand type and recovery rate following experimental harvest. Forest Ecology and Management, 357, 239-247 (2015).

40. Dotzler, S., Hill, J., Buddenbaum, H. \& Stoffels, J., The potential of EnMAP and Sentinel-2 data for detecting drought stress phenomena in deciduous forest communities. Remote Sensing, 7(10), 14227-14258 (2015).

41. Rutkowski, P. et al. Występowanie gleb rdzawych na terenach leśnych zarządzanych przez PGL Lasy Państwowe w świetle danych z Banku Danych o Lasach. (Occurrence of rusty soils in forest areas managed by the State Forests National Forest Holding in the light of data from the Forest Data Bank) Soil Science Annual, 72(4), 143893 https://doi.org/10.37501/soilsa/143893 (2021). 
42. Rutkowski, P., 2008. Woda w ekosystemach leśnych Wielkopolski. (Water in forest ecosystems in Wielkopolska region). Studia i Materiały Centrum Edukacji Przyrodniczo-Leśnej, 10, Zeszyt 2 (18) (2008).

43. Dz.U. Rozporządzenie Ministra środowiska z dnia 15 grudnia 2008 r. w sprawie ustanowienia planu ochrony dla Parku Narodowego "Bory Tucholskie” [Regulation of the Minister of the Environment dated December 15, 2008 on establishing a protection plan for the "Bory Tucholskie" National Park (Journal of Laws, item 1545)] (2008).

44. Henrich, V. et al. Development of an online indices database: Motivation, concept and implementation. 6th EARSeL Imaging Spectroscopy SIG Workshop Innovative Tool for Scientific and Commercial Environment Applications Tel Aviv, Israel, March 16-18 (2009).

45. Huete, A.R. A soil-adjusted vegetation index (SAVI). Remote Sensing of Environment, 25, Issue 3, Pages 295-309 (1988).

46. Rutkowski, P. Stan i perspektywy rozwoju typologii leśnej w Polsce. (State and perspectives of forest typology in Poland). Wyd. Uniw. Przyr. w Poznaniu. Rozpr. nauk. nr 436, s. 248 (2012).

47. Lim, H. et al. Inter-annual variability of precipitation constrains the production response of boreal Pinus sylvestris to nitrogen fertilization. Forest Ecology and Management, 348, 31-45 (2015).

48. Yuan, Z. Y. \& Chen, H. Y. Fine root biomass, production, turnover rates, and nutrient contents in boreal forest ecosystems in relation to species, climate, fertility, and stand age: literature review and metaanalyses. Critical Reviews in Plant Sciences, 29(4), 204-221 (2010).

49. Li, H. et al. Satellite monitoring of boreal forest phenology and its climatic responses in Eurasia. International Journal of Remote Sensing, 38(19), 5446-5463 (2017).

\section{Figures}




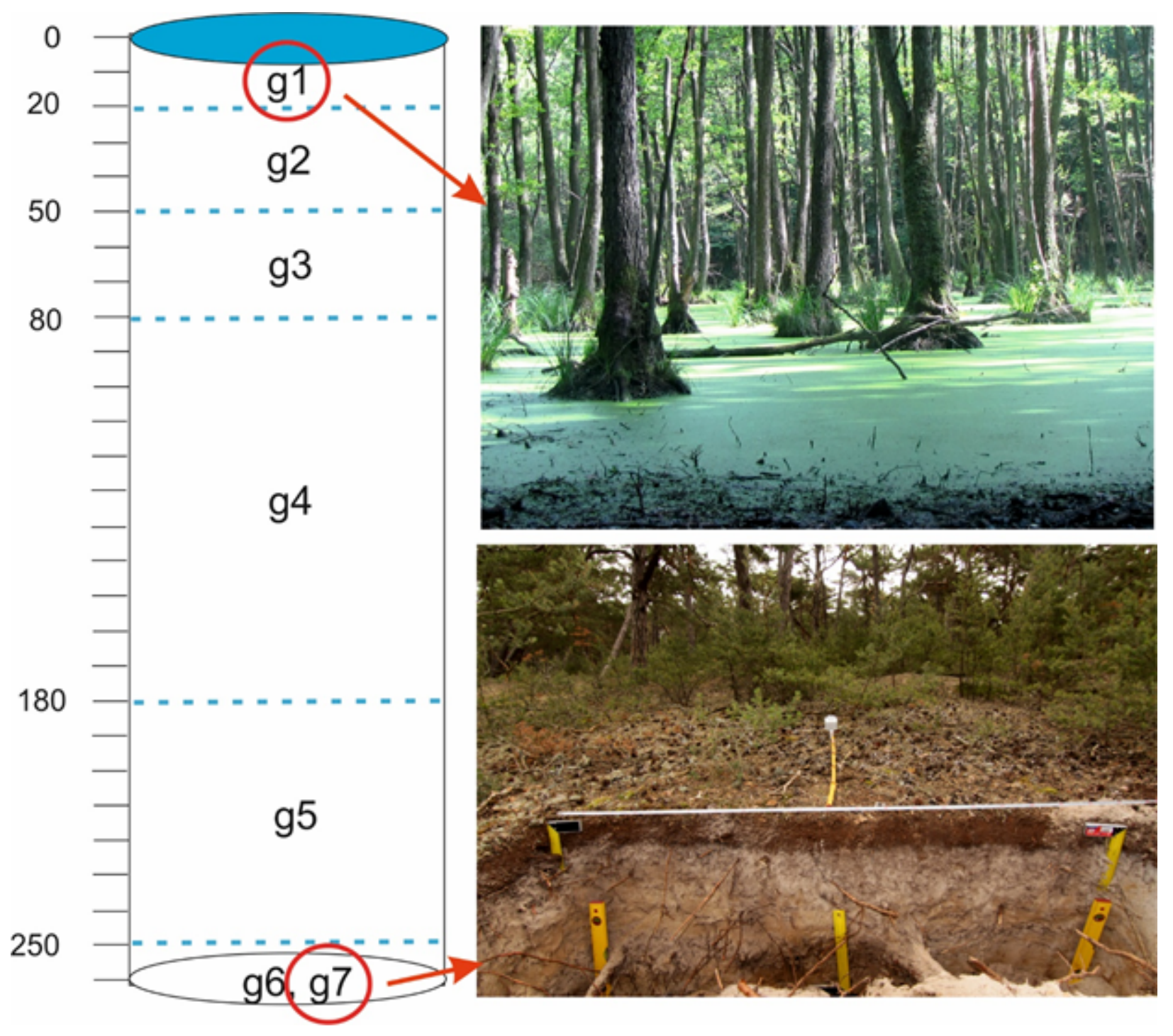

Figure 1

The depth of groundwater occurrence (in $\mathrm{cm}$ ) for each Forest Habitats Moisture Index (figure and photos: by authors) 


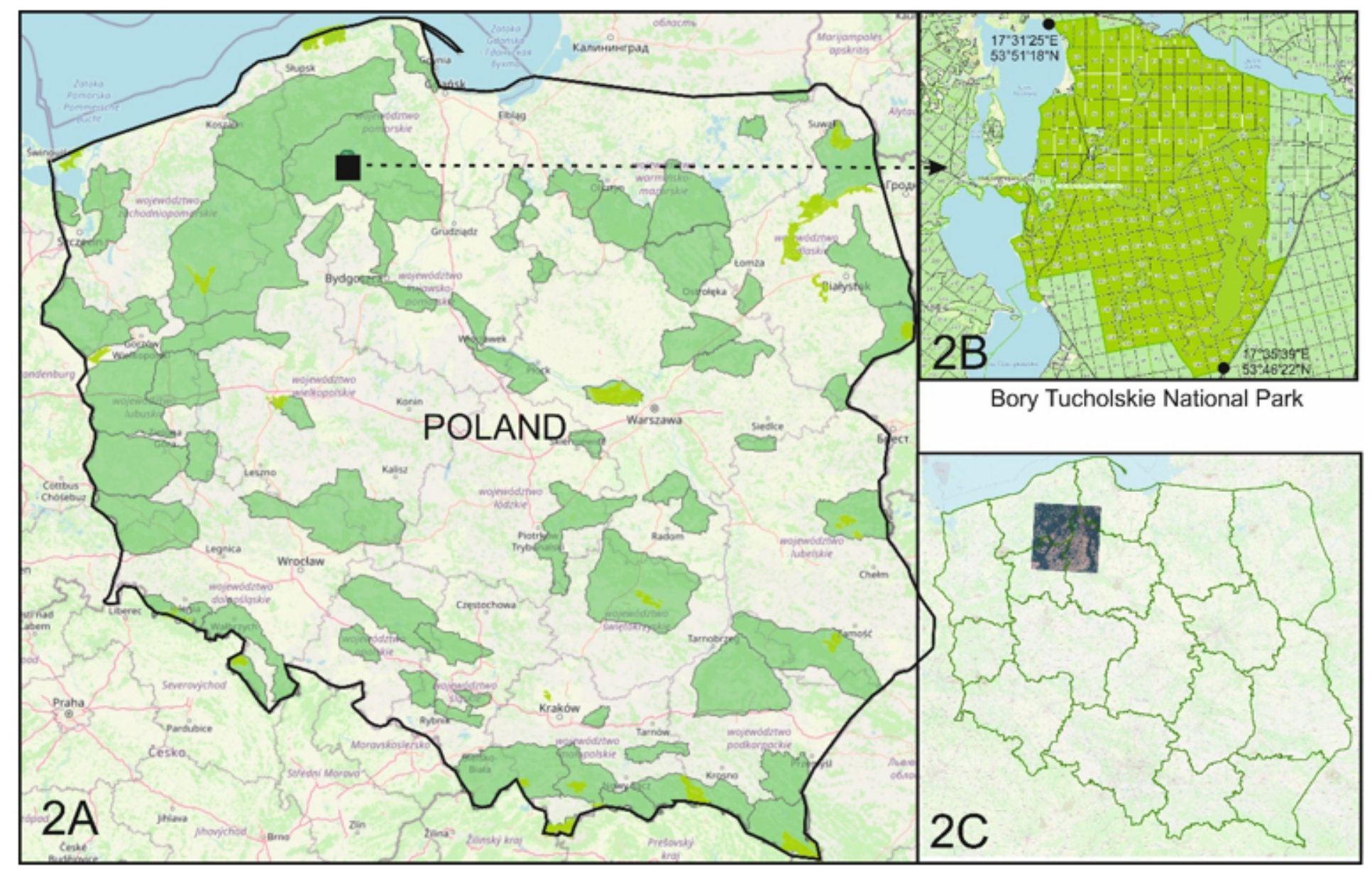

Figure 2

Location of the research area. 2A - research area on the background of the map of Poland. The main forest complexes are marked with green contours; 2B - Bory Tucholskie National Park area (green); 2C shows the satellite image on the background of the map of Poland used in the research 


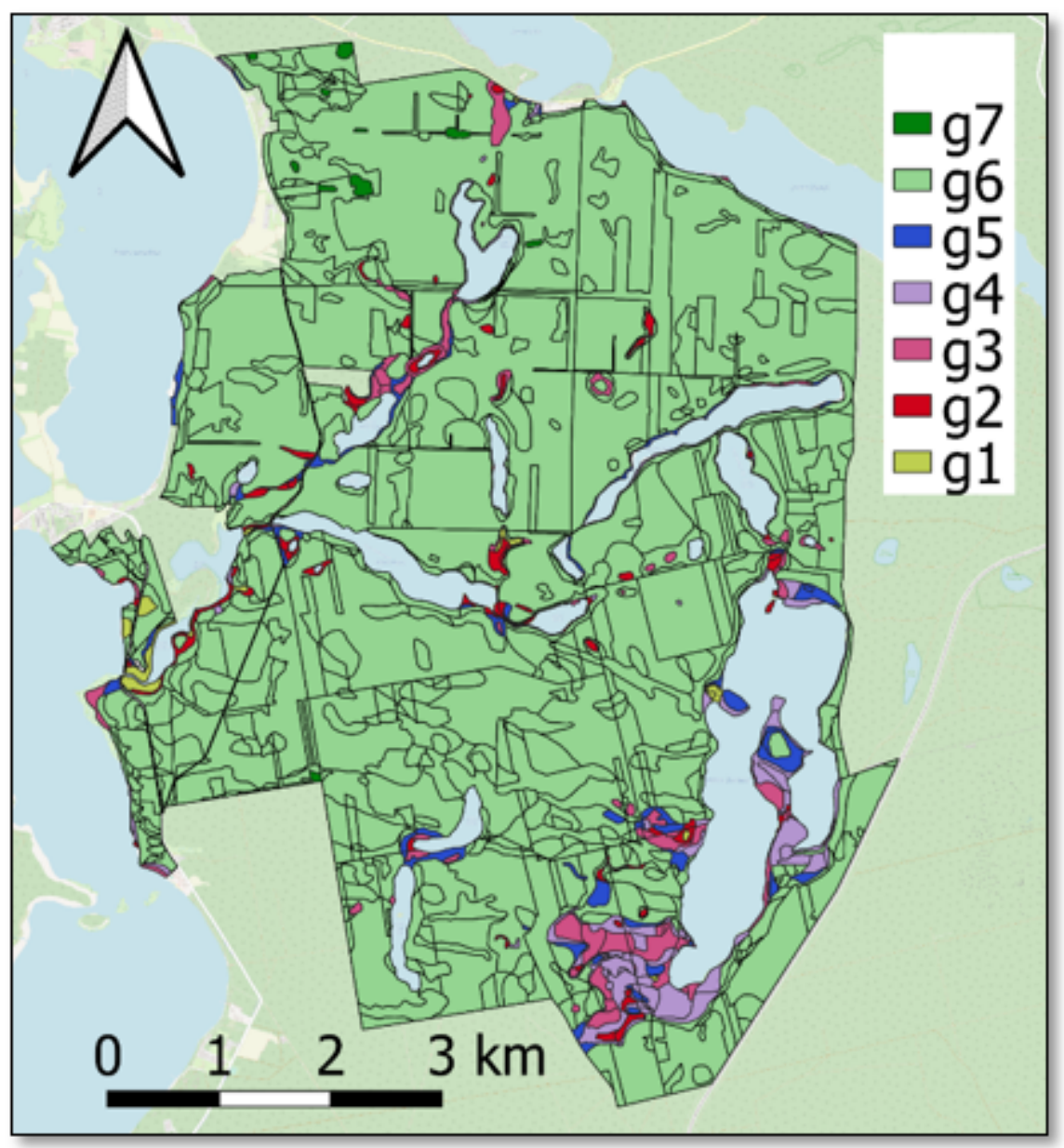

Figure 3

Map of humidity variation in Bory Tucholskie National Park, expressed in FHMls (g1-g7) 


\section{Chojnice weather station}

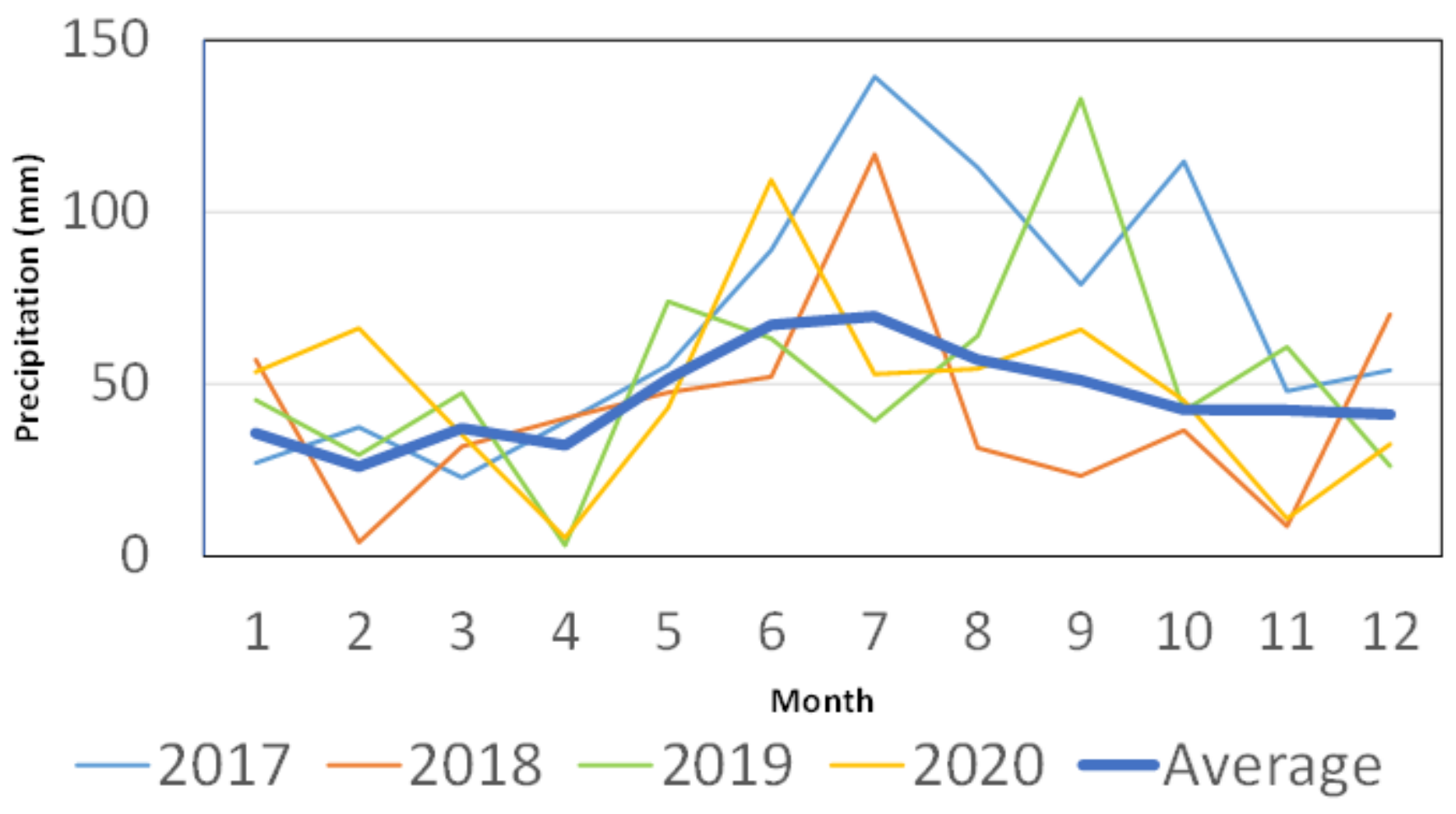

Figure 4

Variability of month sum of precipitation within the period from 2017 to 2020 


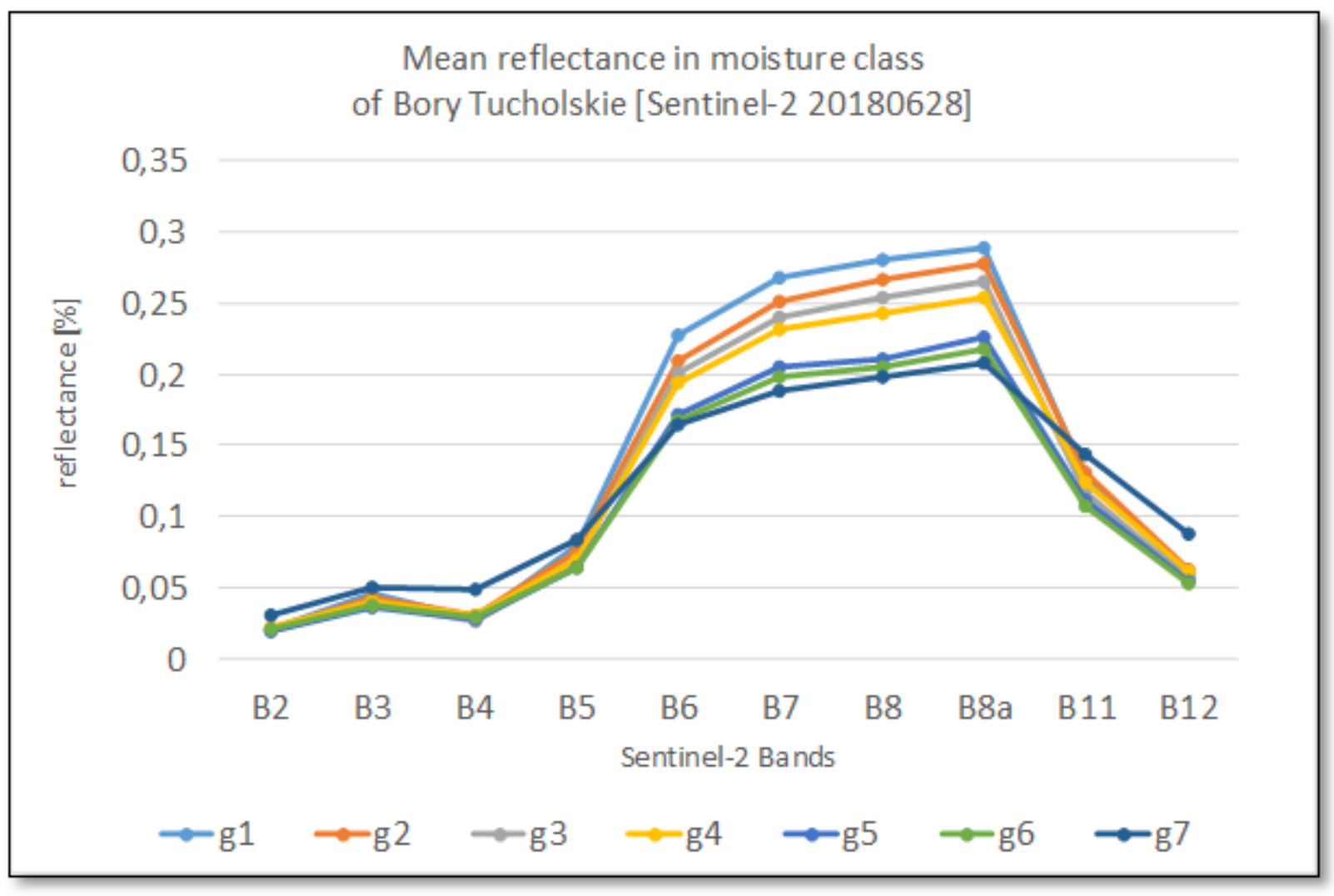

Figure 5

Spectral curves of seven FHMI in Bory Tucholskie based on the Sentinel-2 image recorded on 28 June 2018

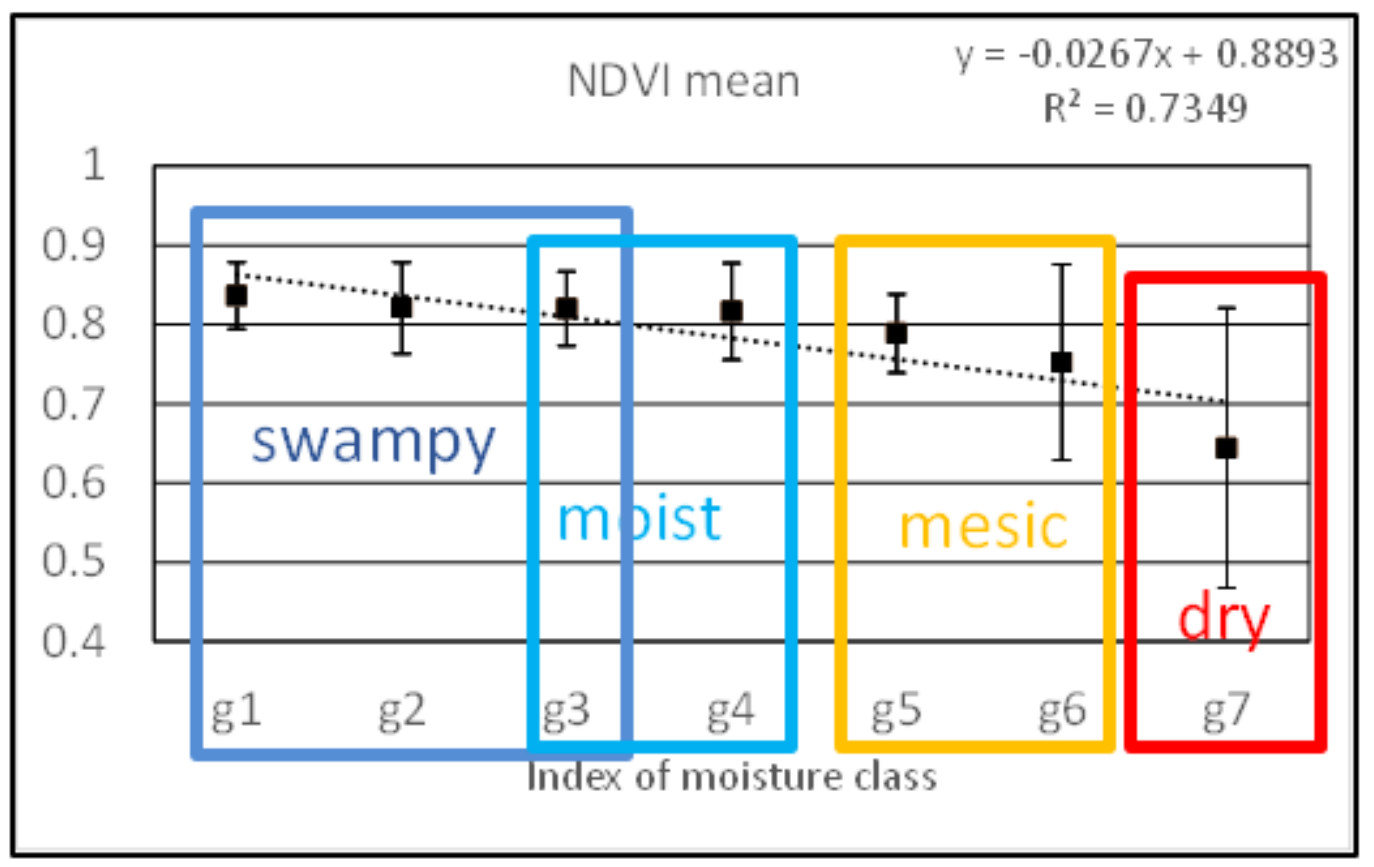


Figure 6

Fig. 6. Mean NDVI value for data as of 20 June 2018, taking into account all FHMls (g1-g7)

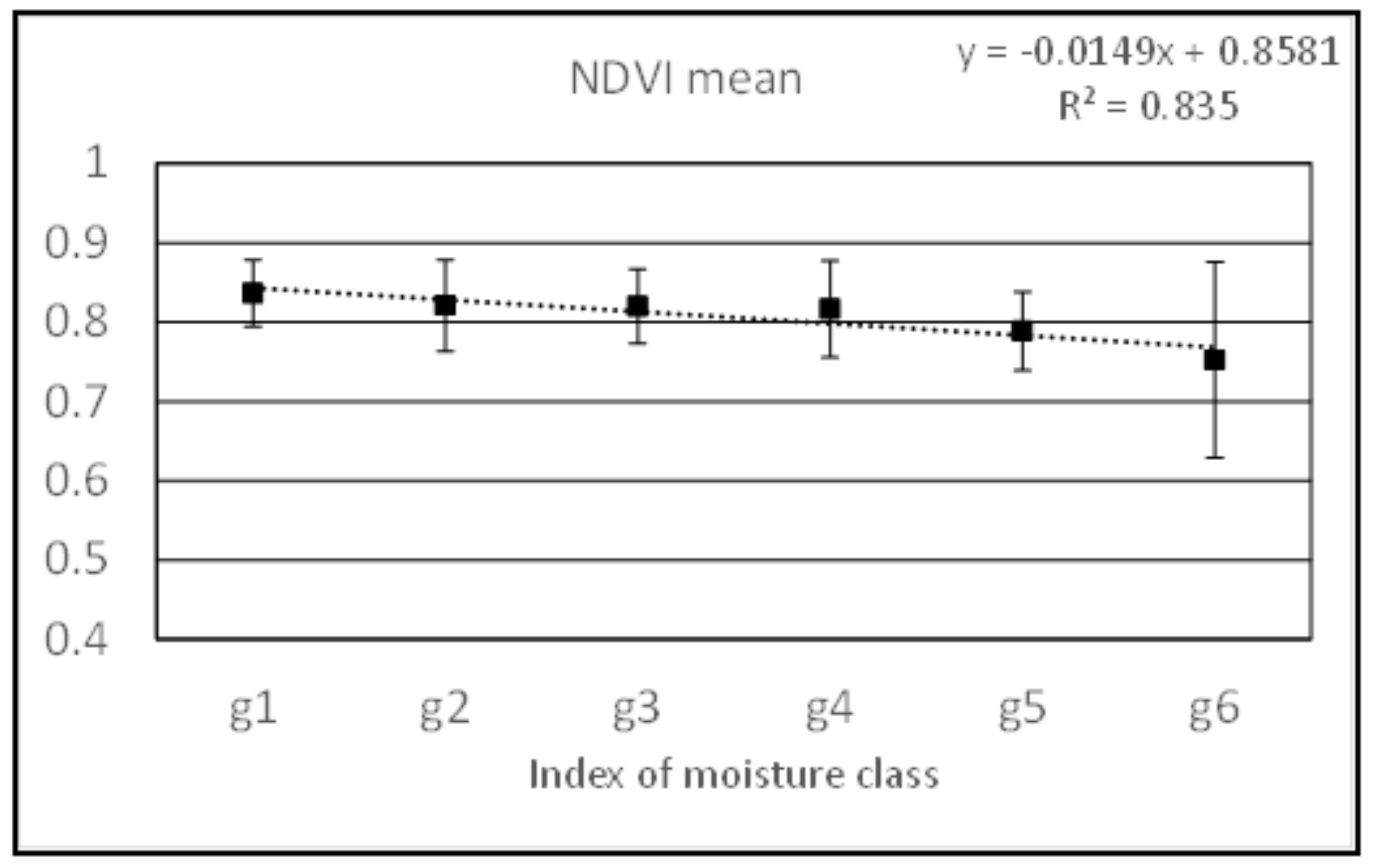

Figure 7

Mean NDVI value for data as of 20 June 2018, excluding grade g7

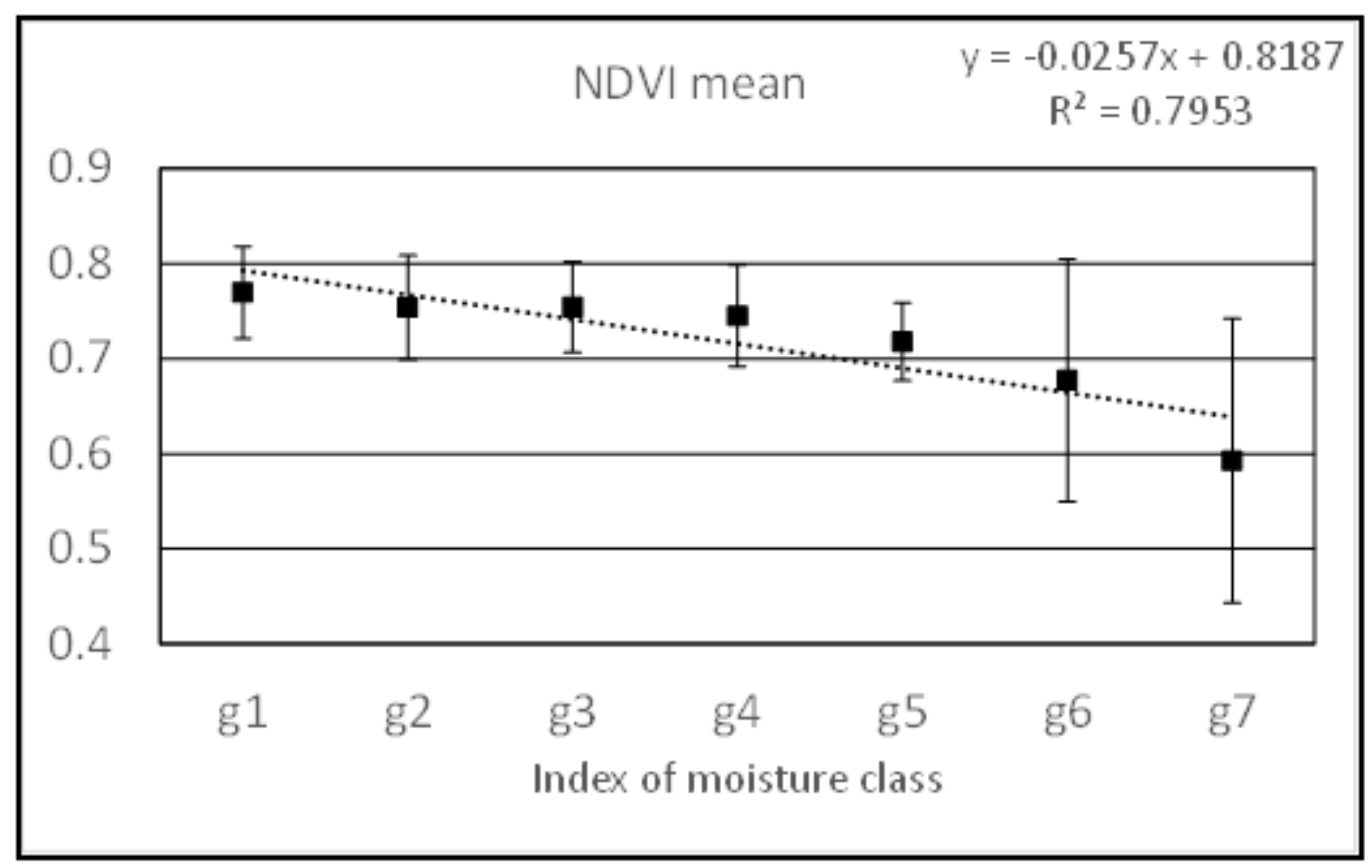

Figure 8

Mean NDVI value for data as of 20 June 2019, taking into account all FHMls (g1-g7) 


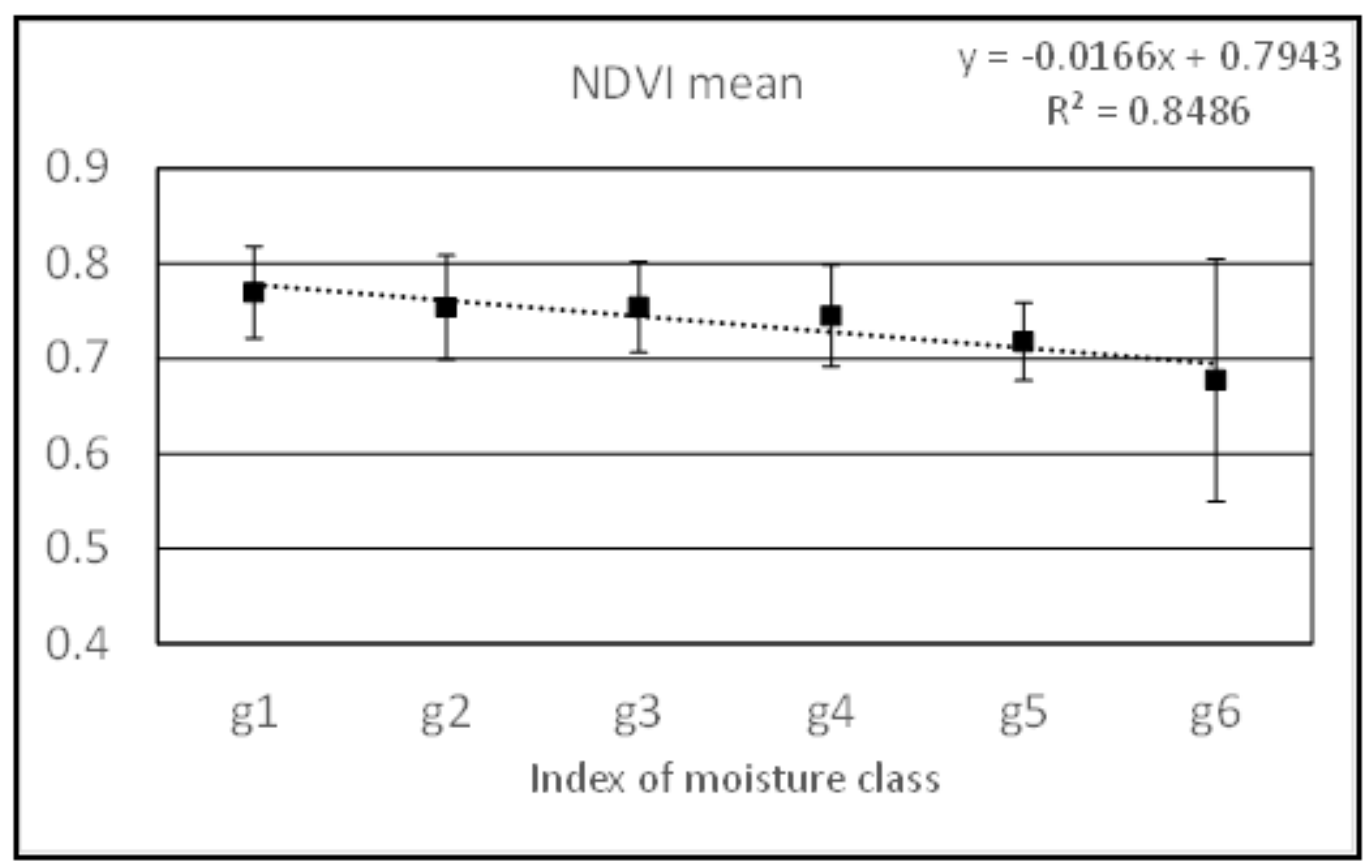

Figure 9

Mean NDVI value for the data as of 20 June 2019, excluding grade g7

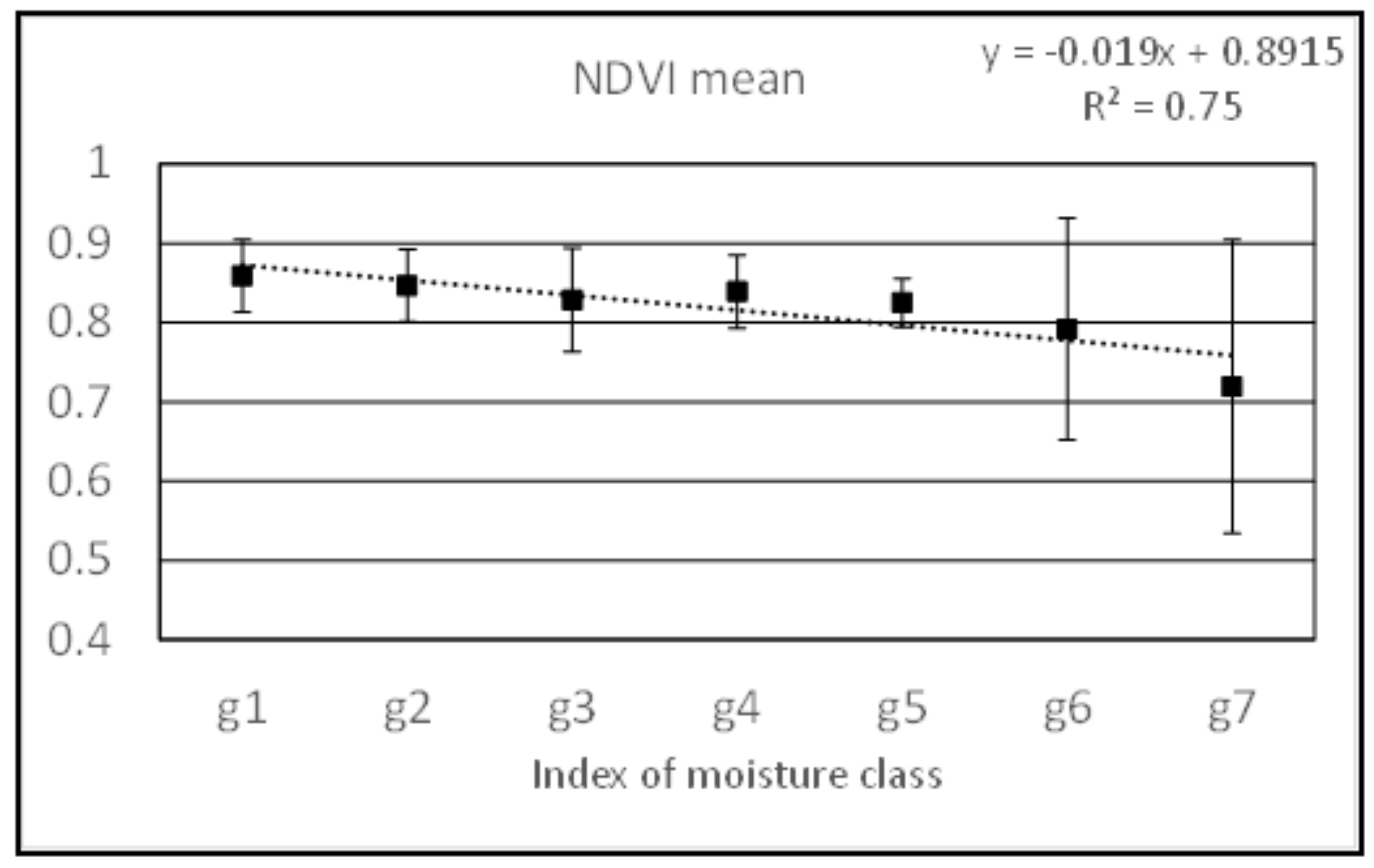

Figure 10

Mean NDVI value for the data as of 06 August 2020, taking into account all FHMls (g1-g7) 


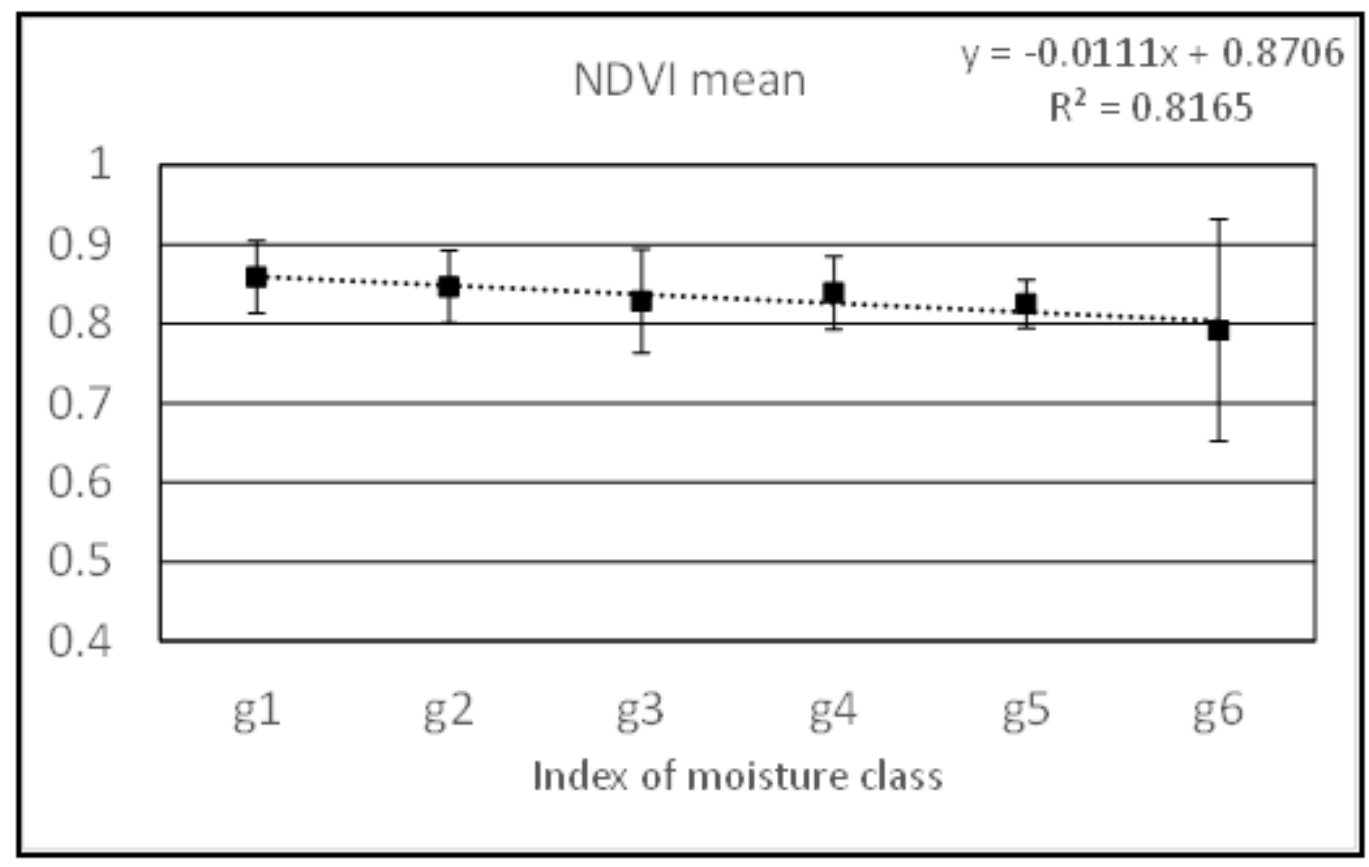

Figure 11

Mean NDVI value for the data as of 06 August 2020, excluding grade g7

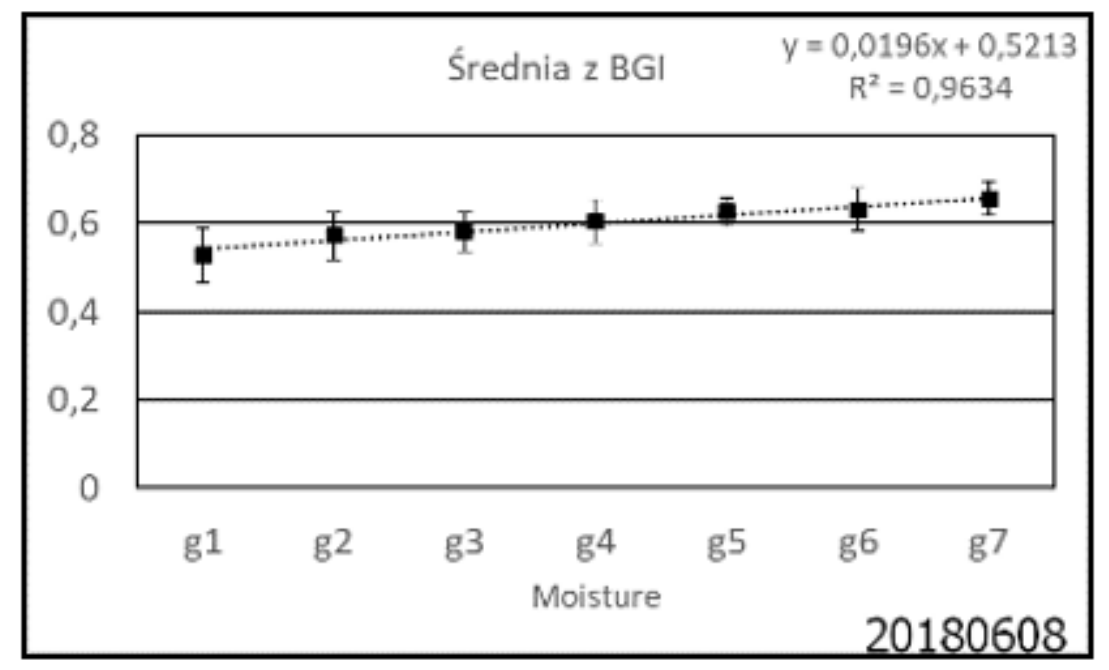

Figure 12

Average BGI value in seven FHMls for the data as of 08 June 2018 


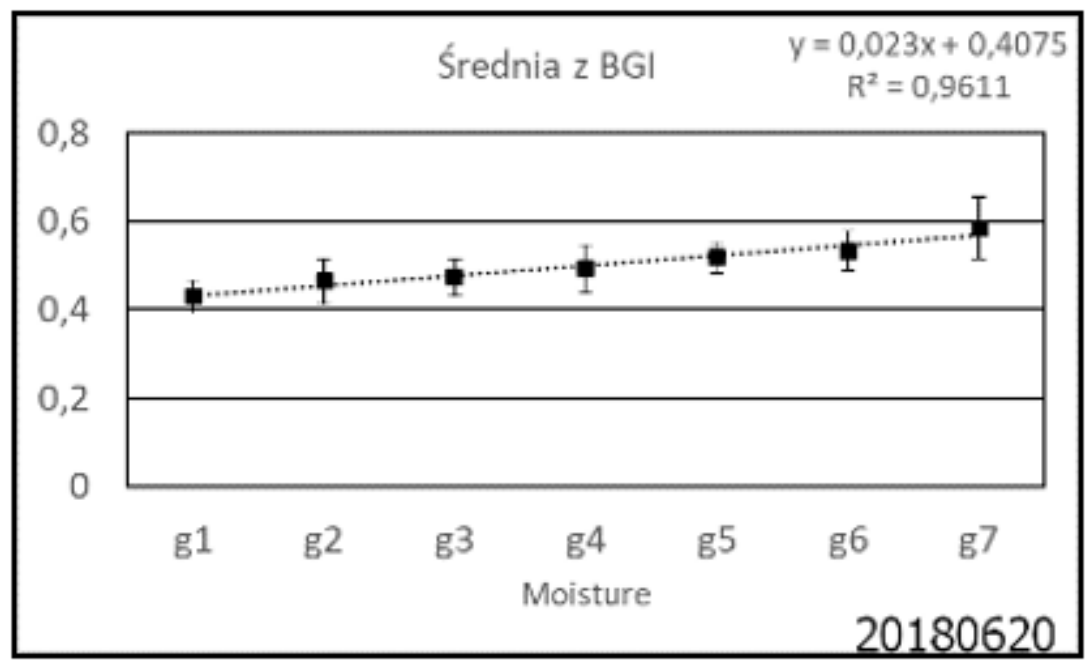

Figure 13

Average BGI value in seven FHMls for the data as of 20 June 2018

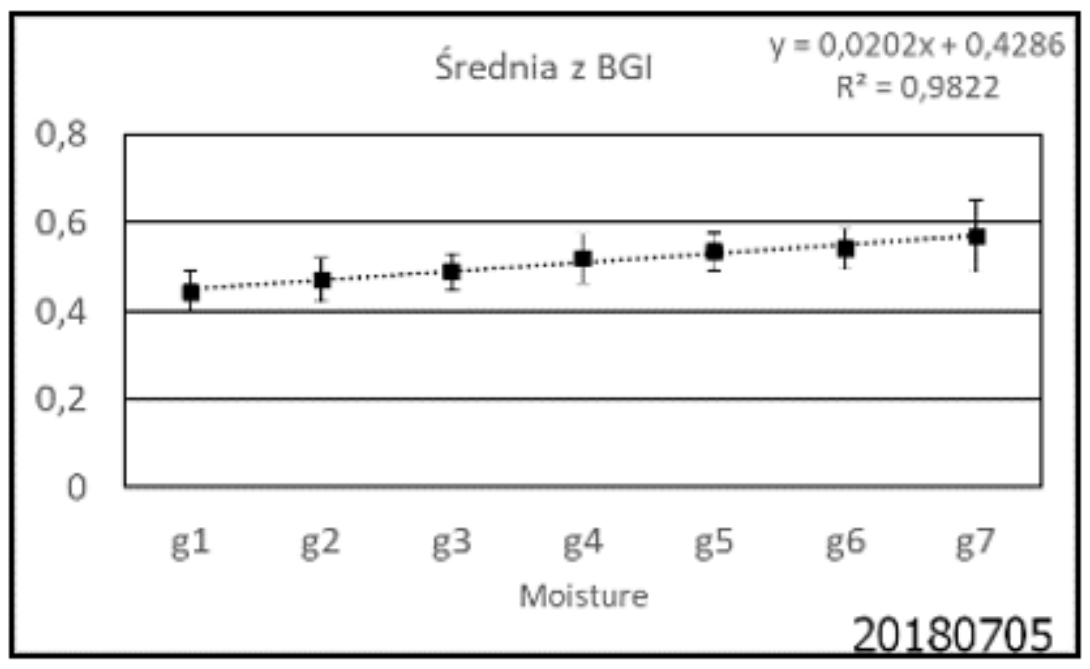

Figure 14

Average BGI value for seven FHMIs for the data from 05 July 2018 


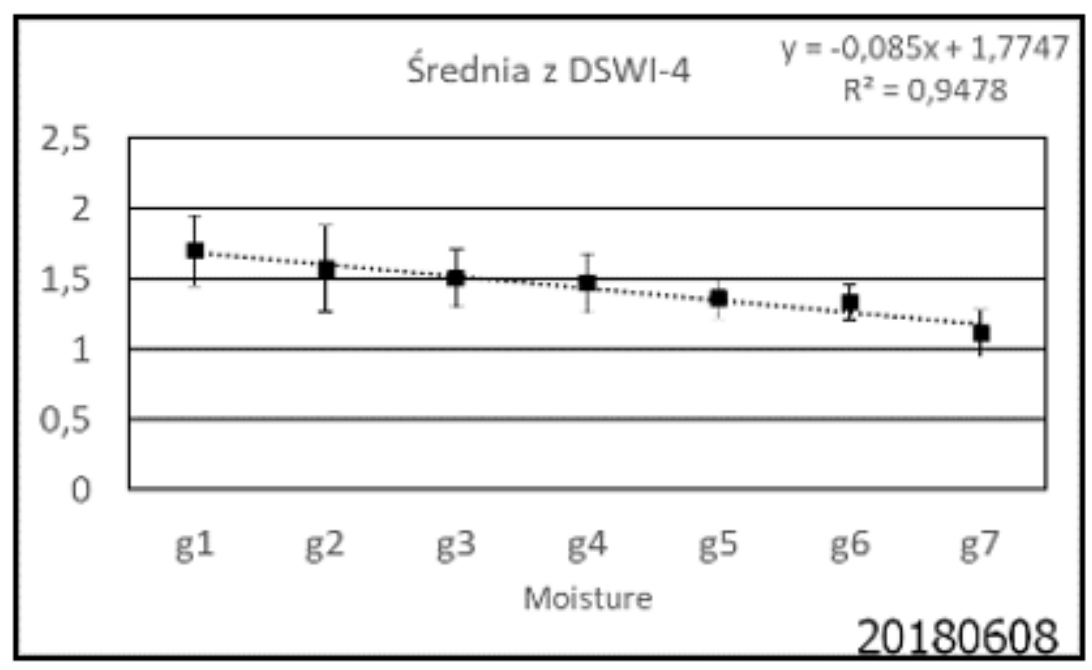

Figure 15

Average value of DSWI-4 in seven FHMIs for data from 08 June 2018

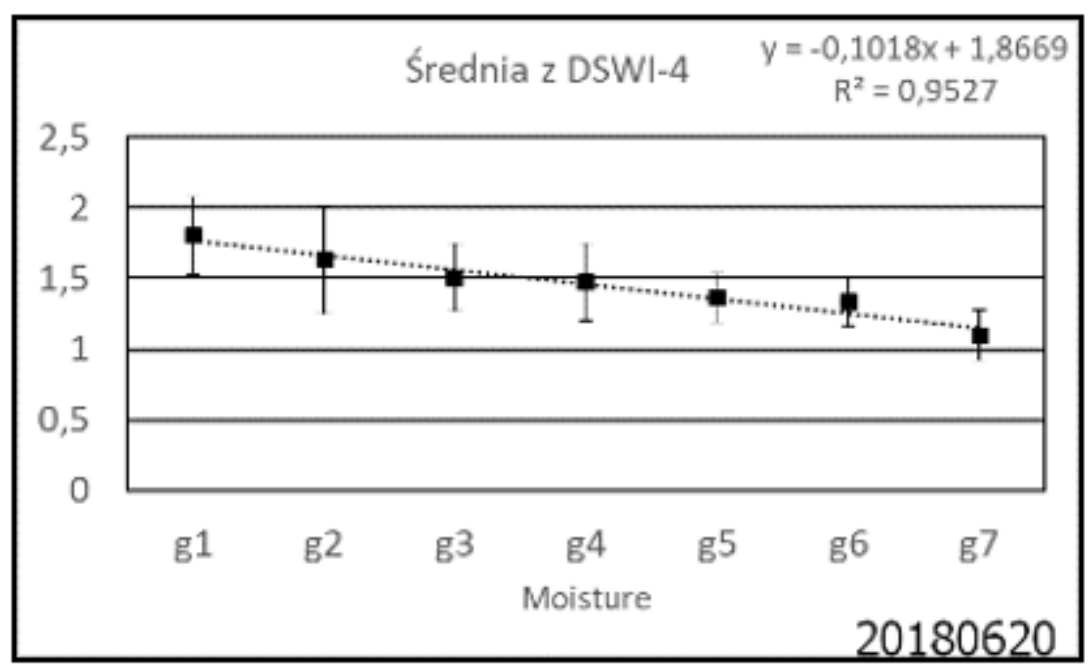

Figure 16

Average value of DSWI-4 in seven FHMIs for data from 20 June 2018 


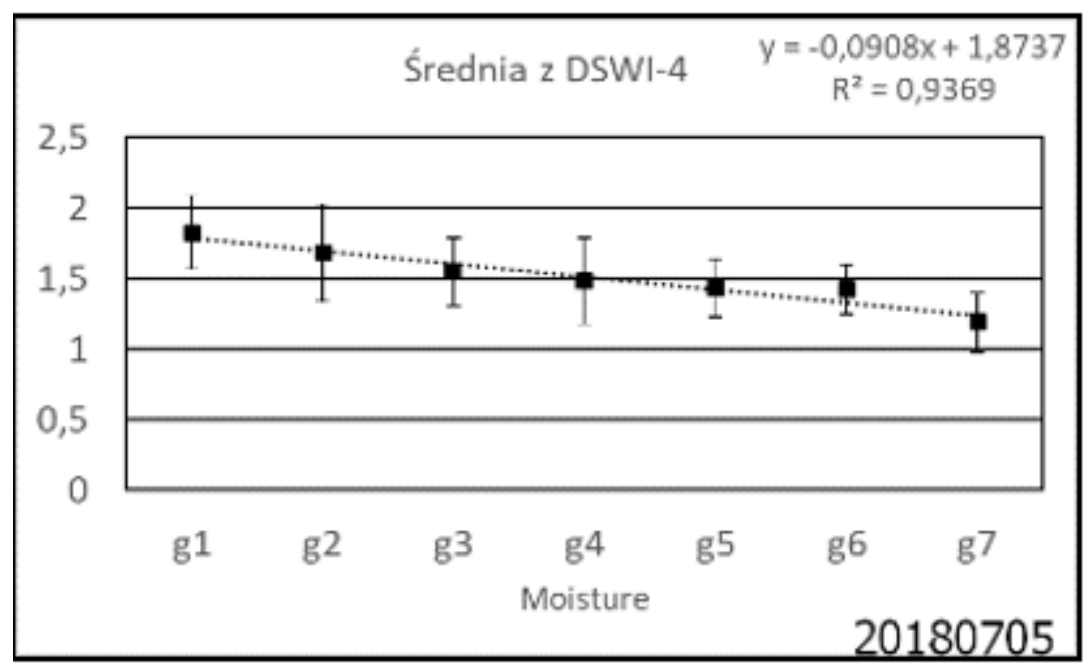

Figure 17

Average value of DSWI-4 in seven FHMIs for data from 05 July 2018

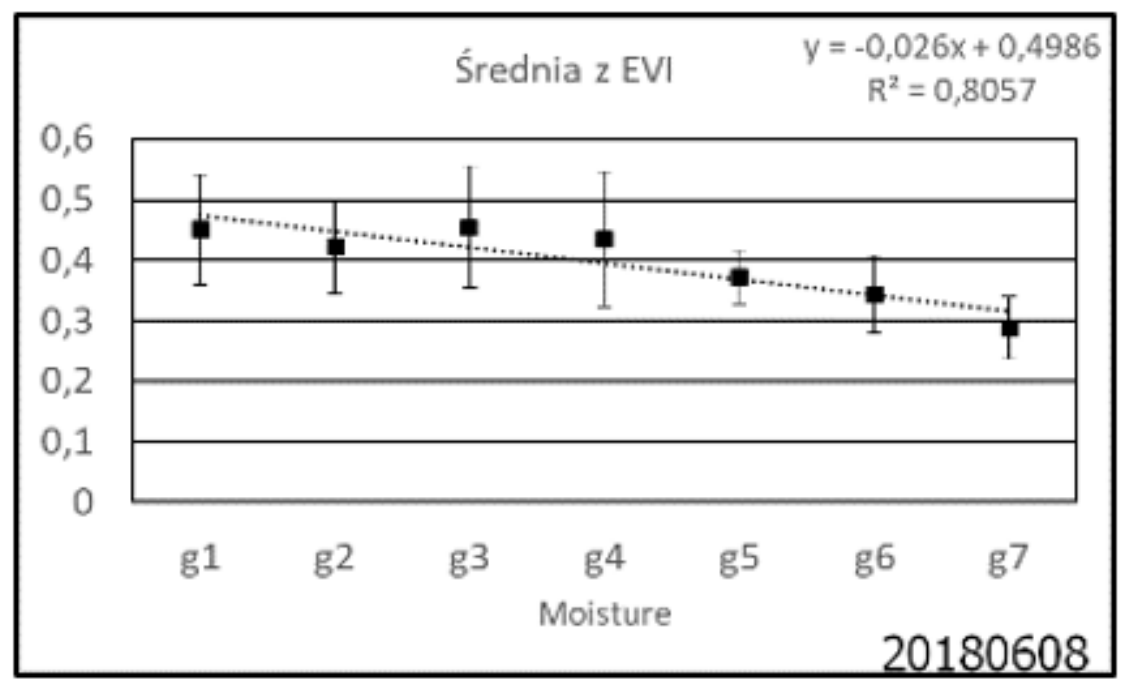

Figure 18

Average EVI value in seven FHMIs for the data as of 08 June 2018 


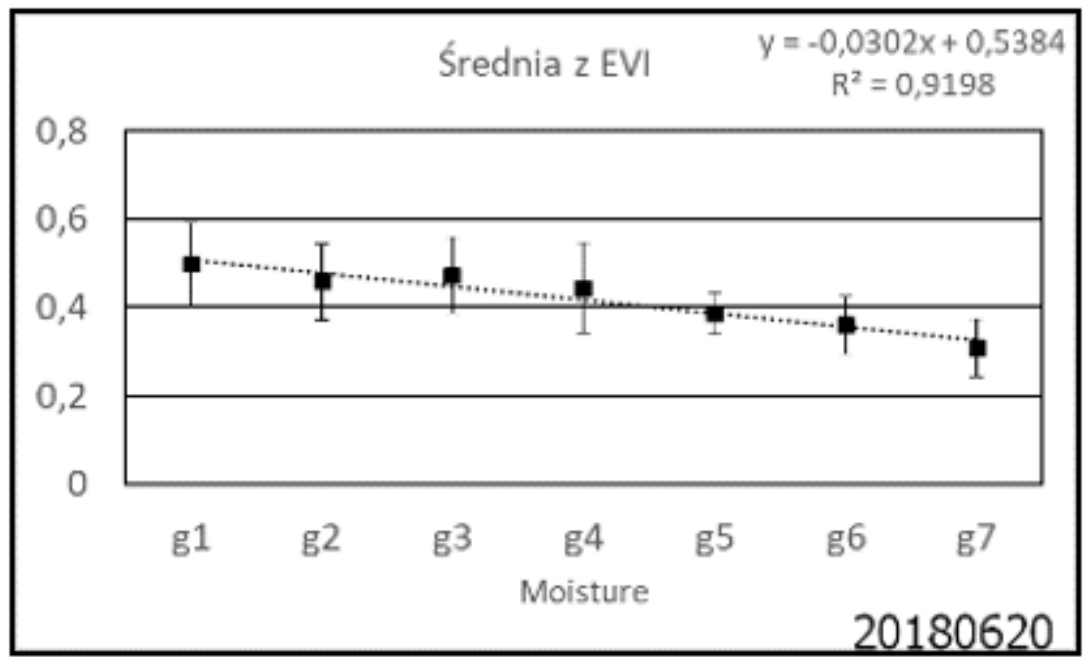

Figure 19

Average EVI value in the seven FHMls for the data as of 20 June 2018

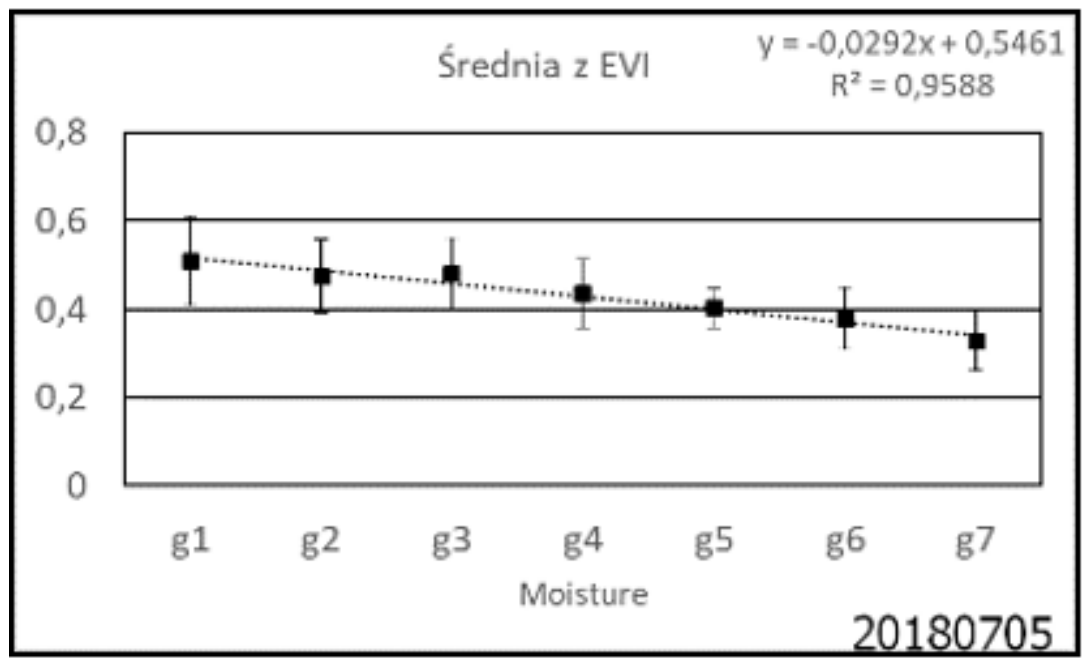

Figure 20

Average EVI value in seven FHMIs for the data from 05 July 2018 


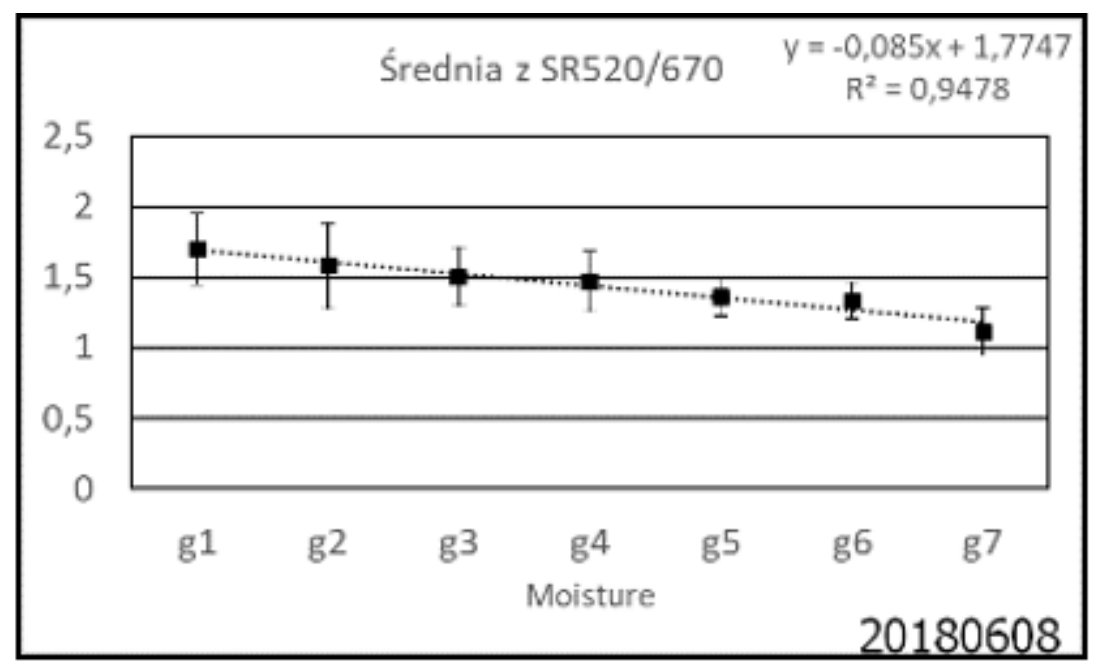

Figure 21

Average value of SR520/670 in seven FHMls for data from 08 June 2018

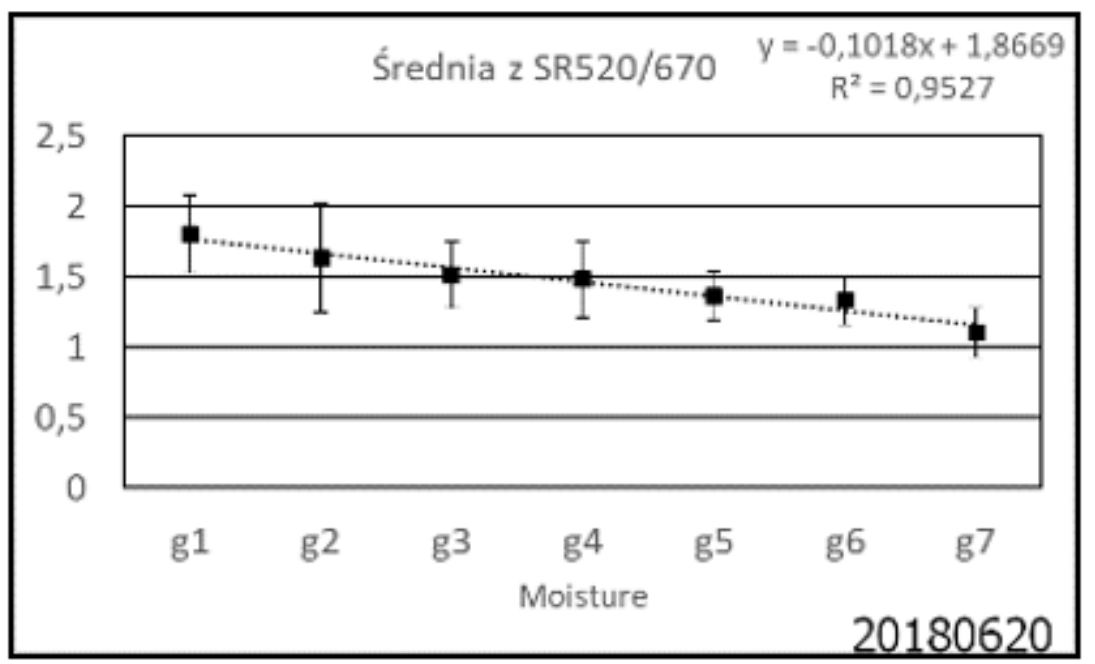

Figure 22

Average value of SR520/670 in seven FHMls for data from 20 June 2018 


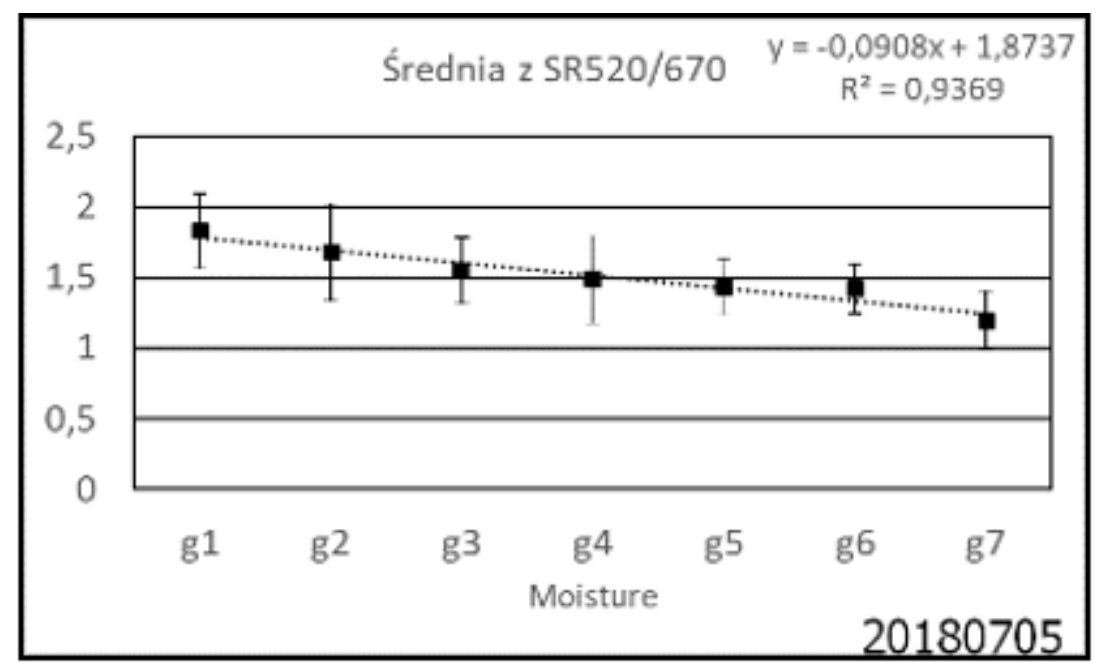

Figure 23

Average value of SR520/670 in seven FHMIs for data from 05 July 2018

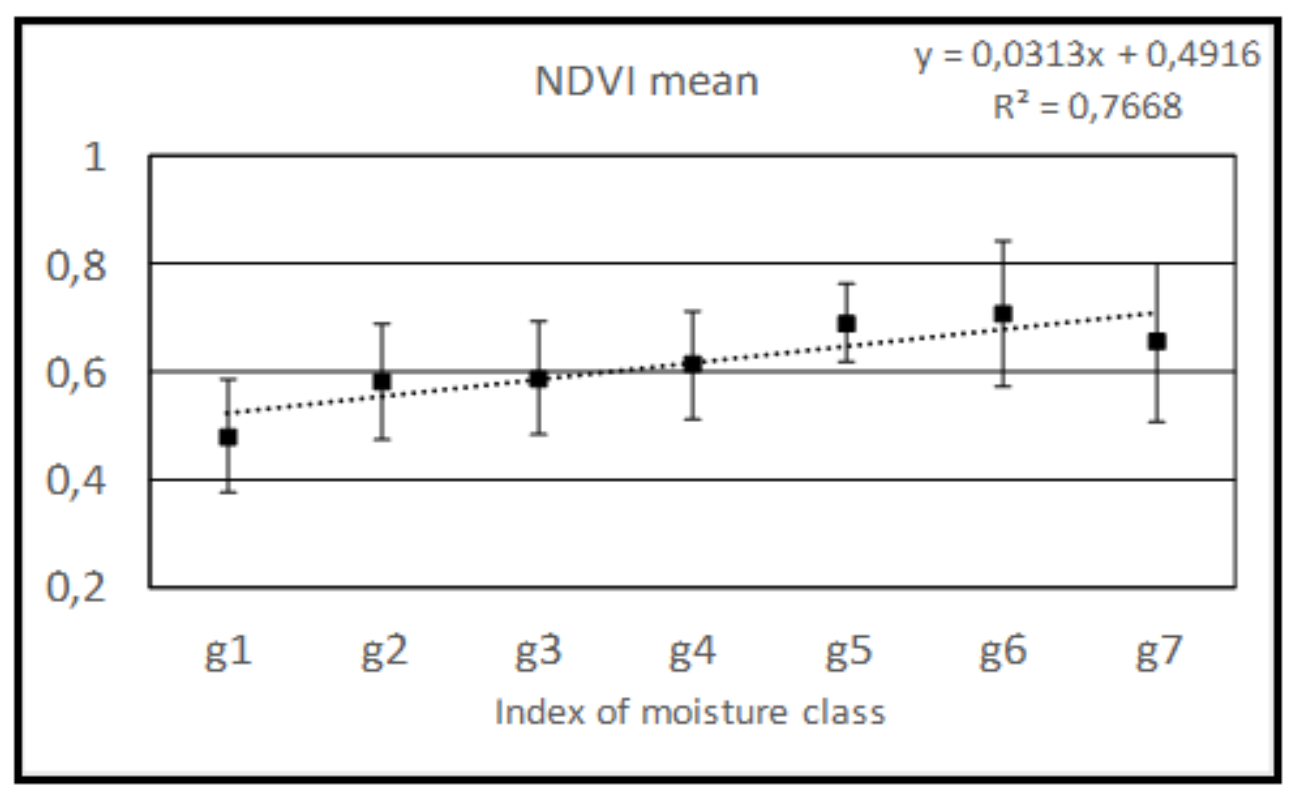

Figure 24

Average NDVI value for data as of 26 March 2020 


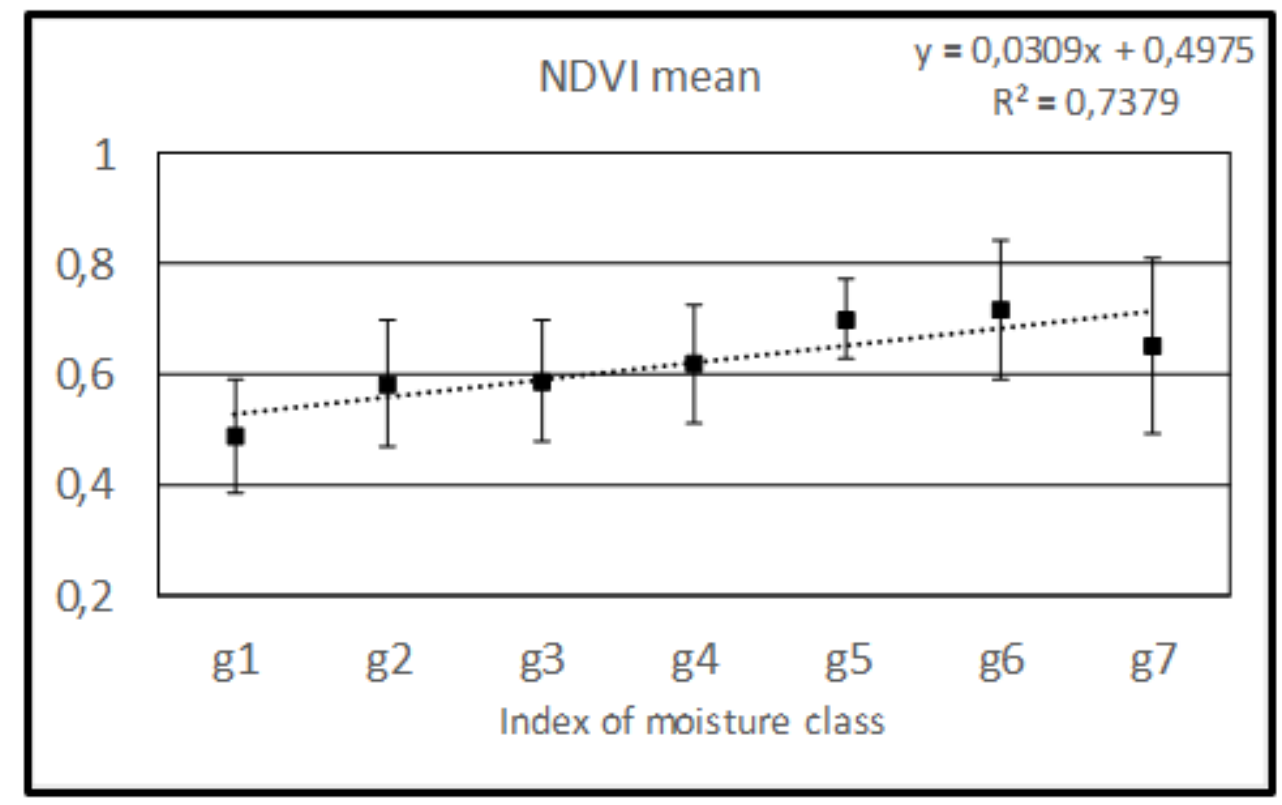

Figure 25

Average NDVI value for data as of 05 April 2020

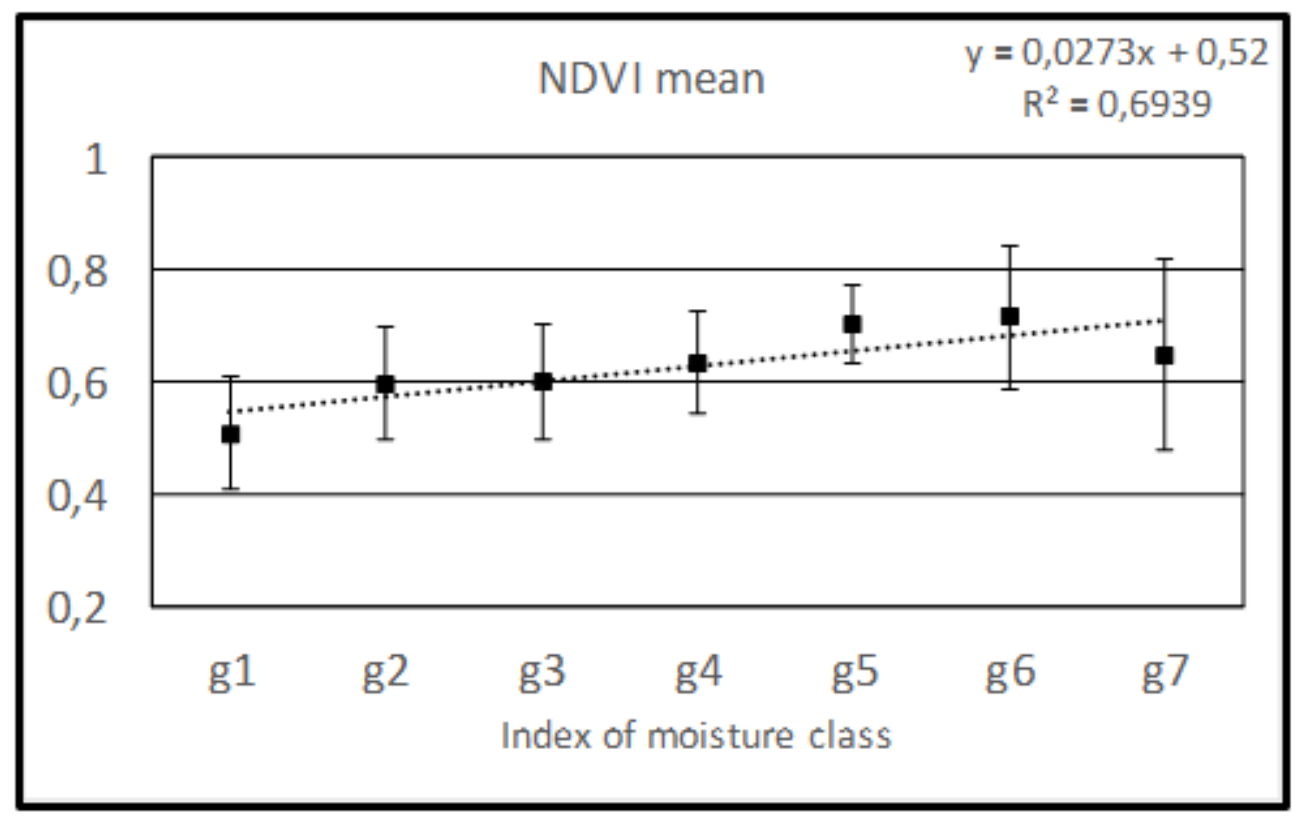

Figure 26

Average NDVI value for data as of 23 April 2020 


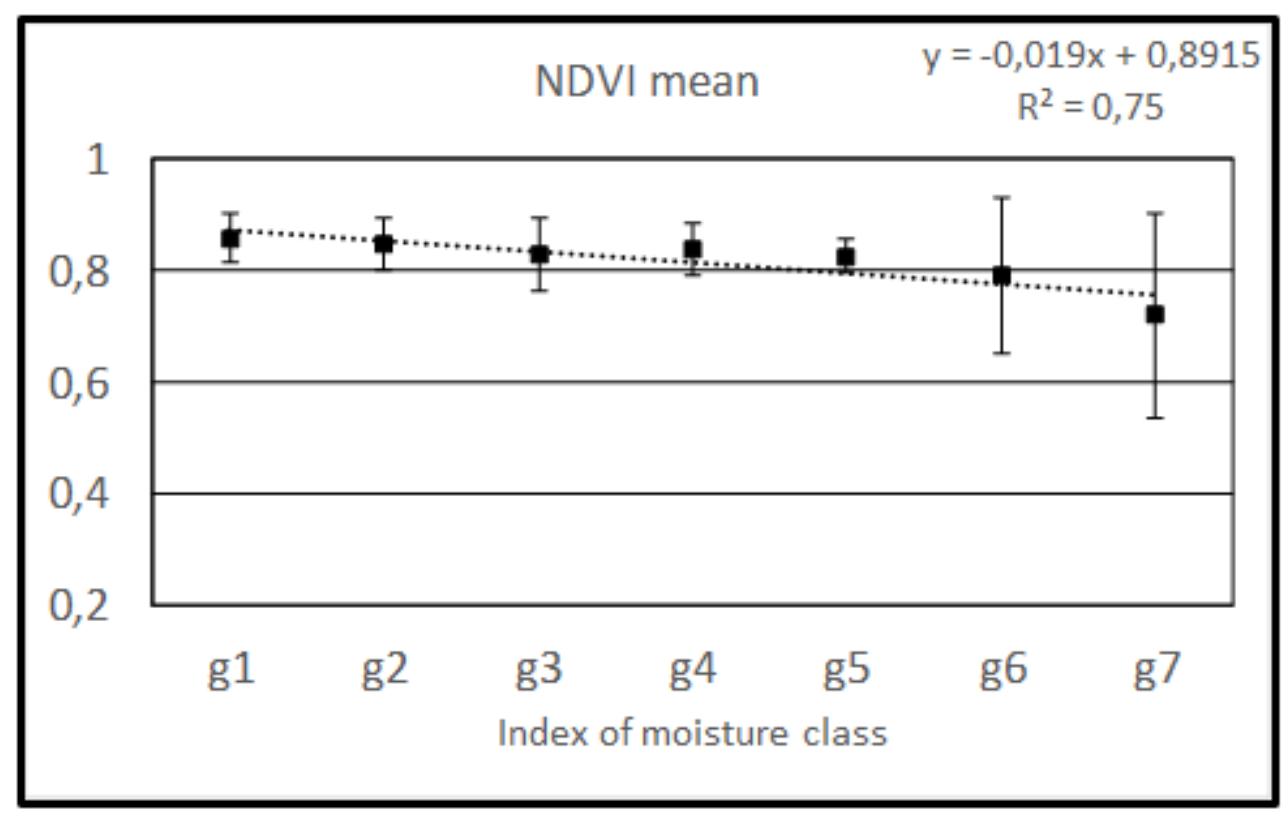

Figure 27

Average NDVI value for data as of 06 August 2020

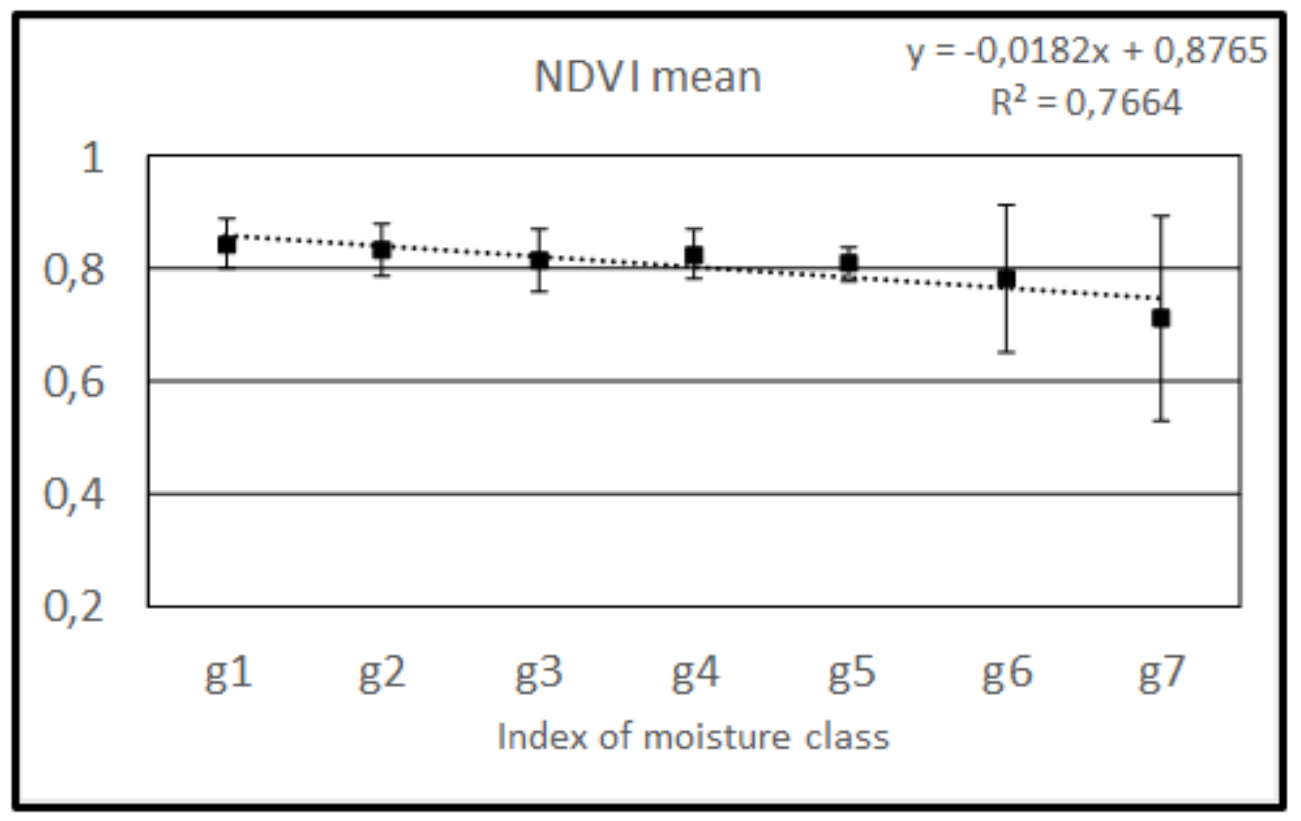

Figure 28

Average NDVI value for data as of 11 August 2020 


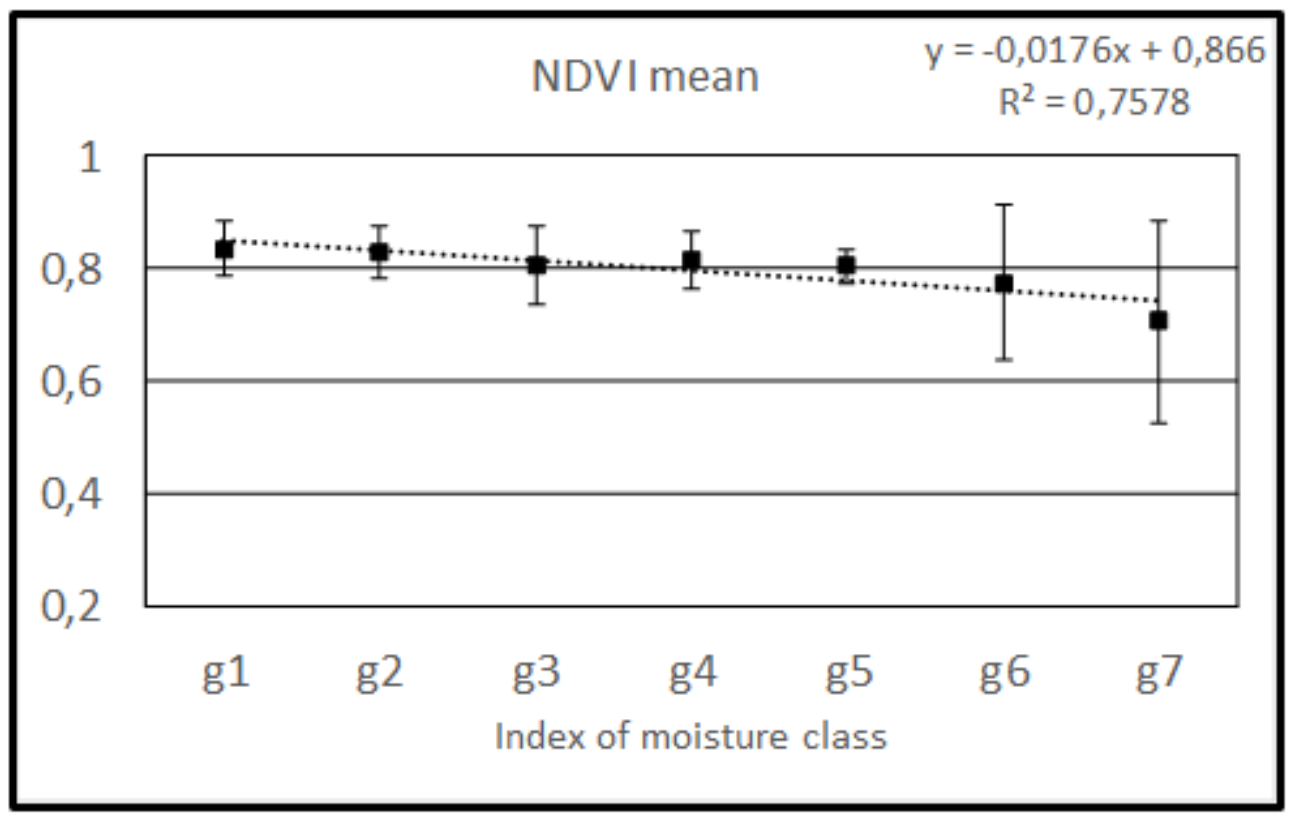

Figure 29

Average NDVI value for data as of 16 August 2020

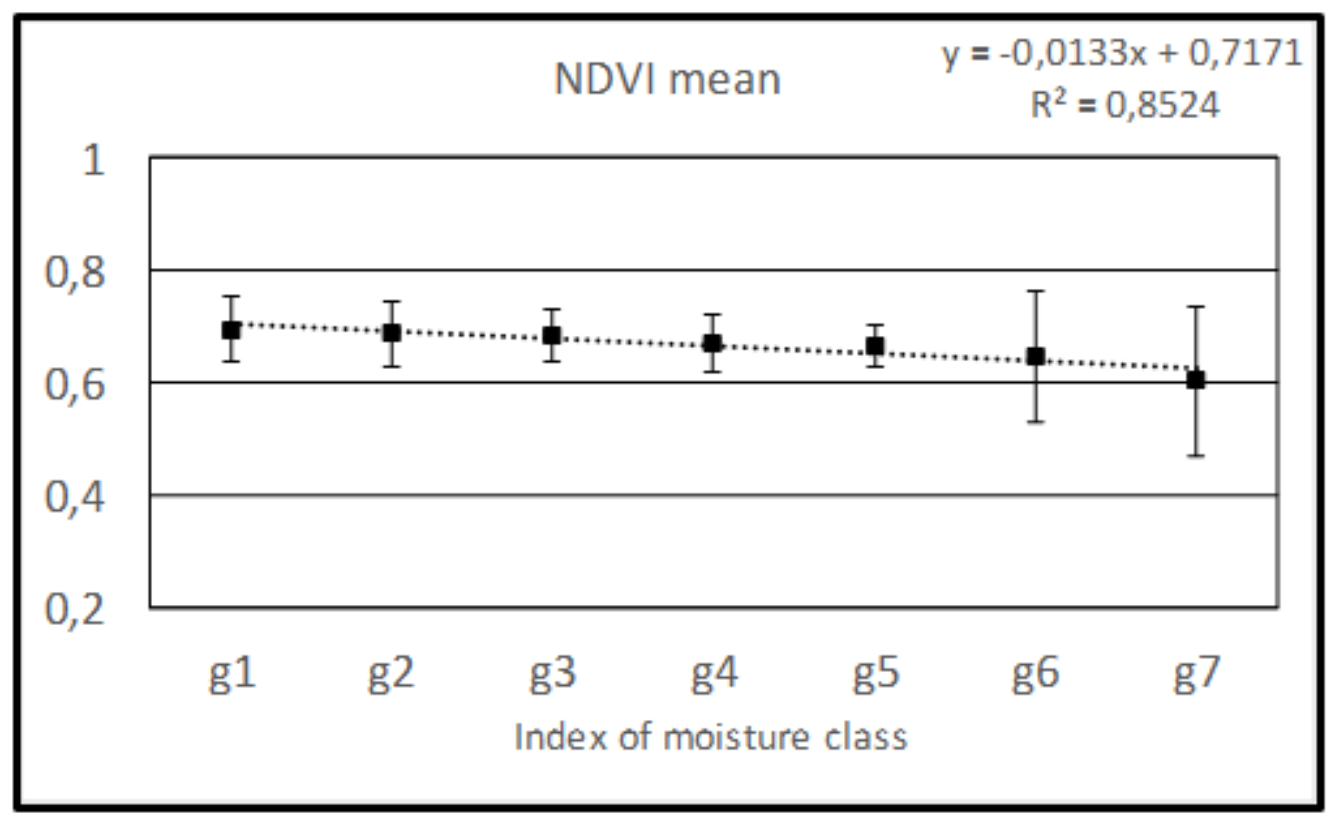

Figure 30

Average NDVI value for data as of 12 September 2020 


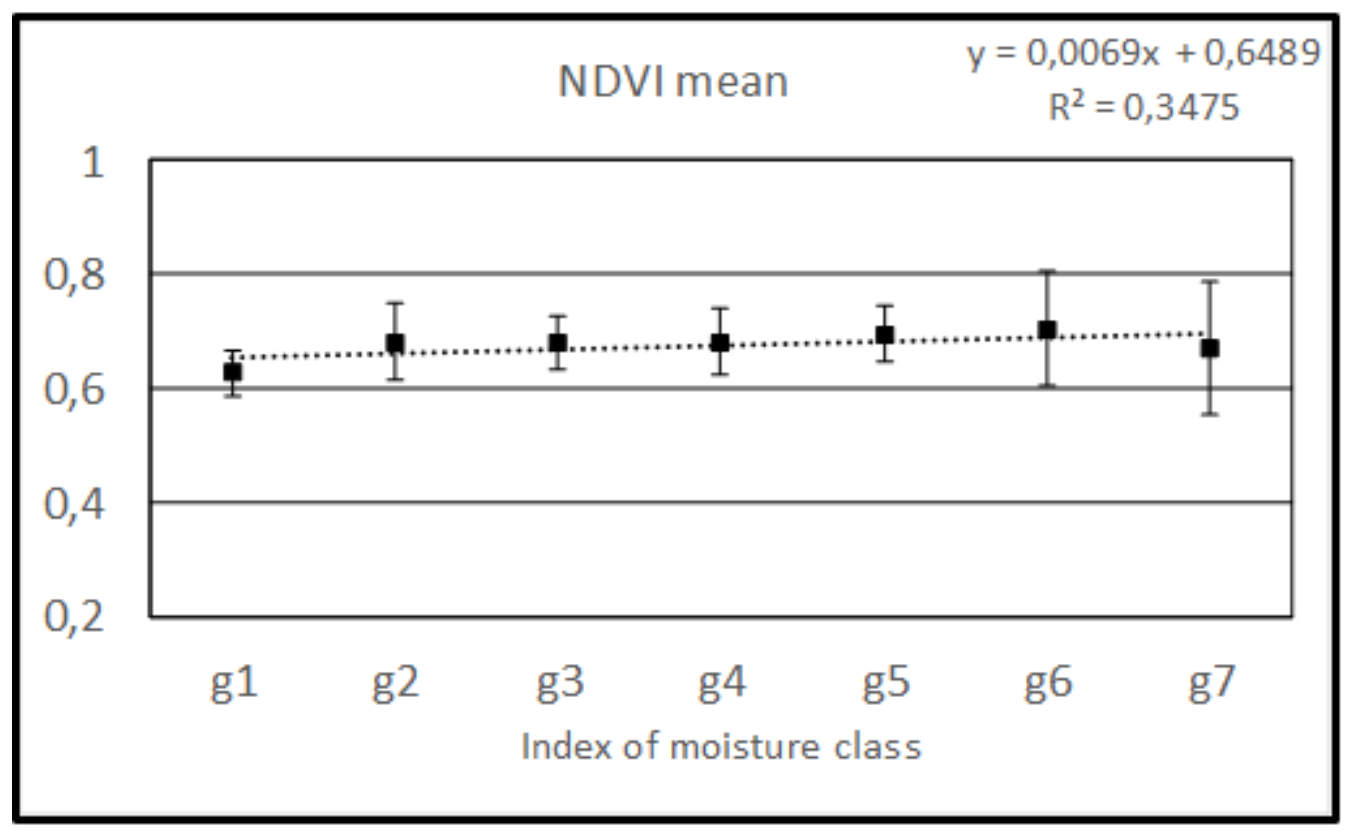

Figure 31

Average NDVI value for data as of 25 October 2020The dormant period has begun and the trend has changed

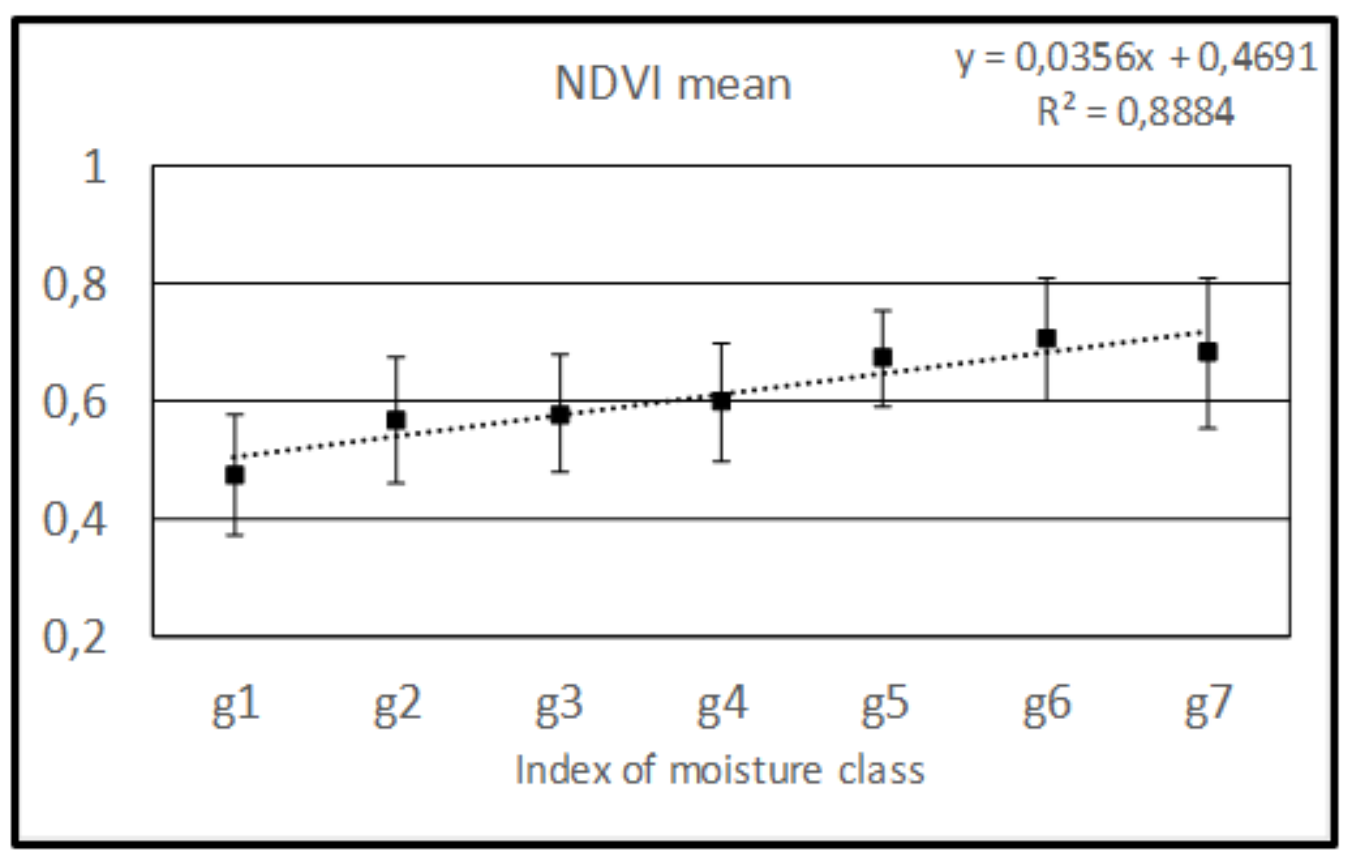

Figure 32

Average NDVI value for data as of 26 December 2020The period of vegetative dormancy 

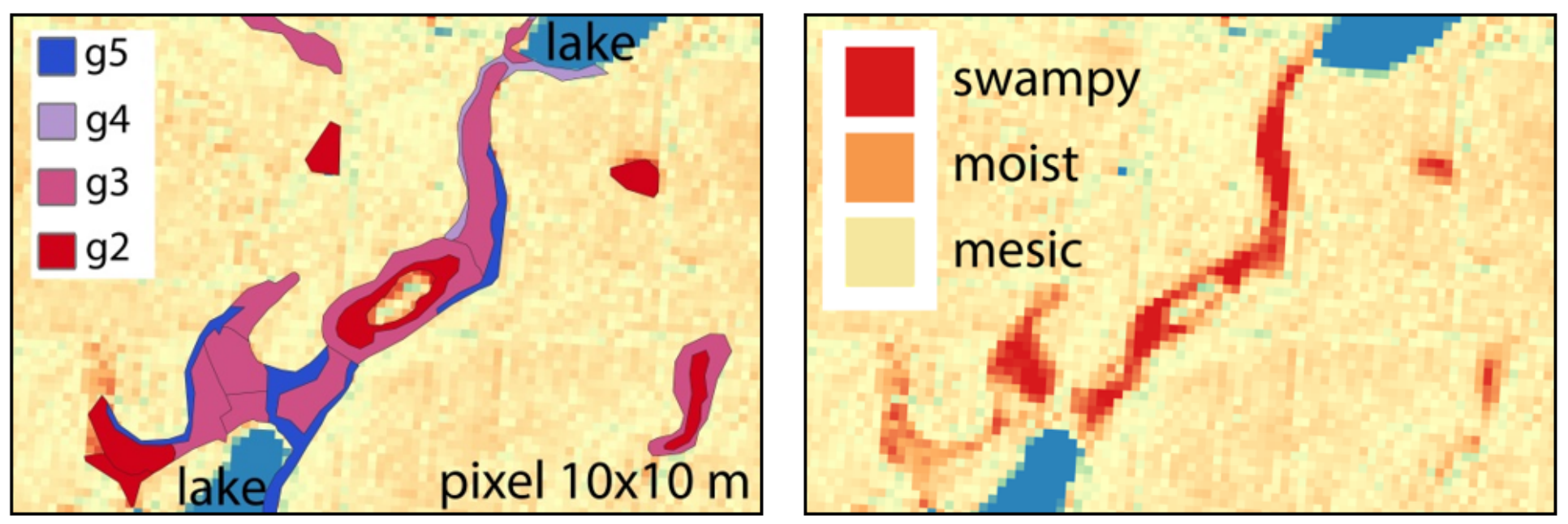

Figure 33

Comparison of the image of a fragment of the habitat map made with the traditional method of soil pits (left) with the image of the same area differentiated due to the NDVI values (right). Only g2-g5 FHMIs are included in the image legend on the left. The main background of the picture shows the g6 FHMI. The g1 and g7 FHMls do not exist in the presented area
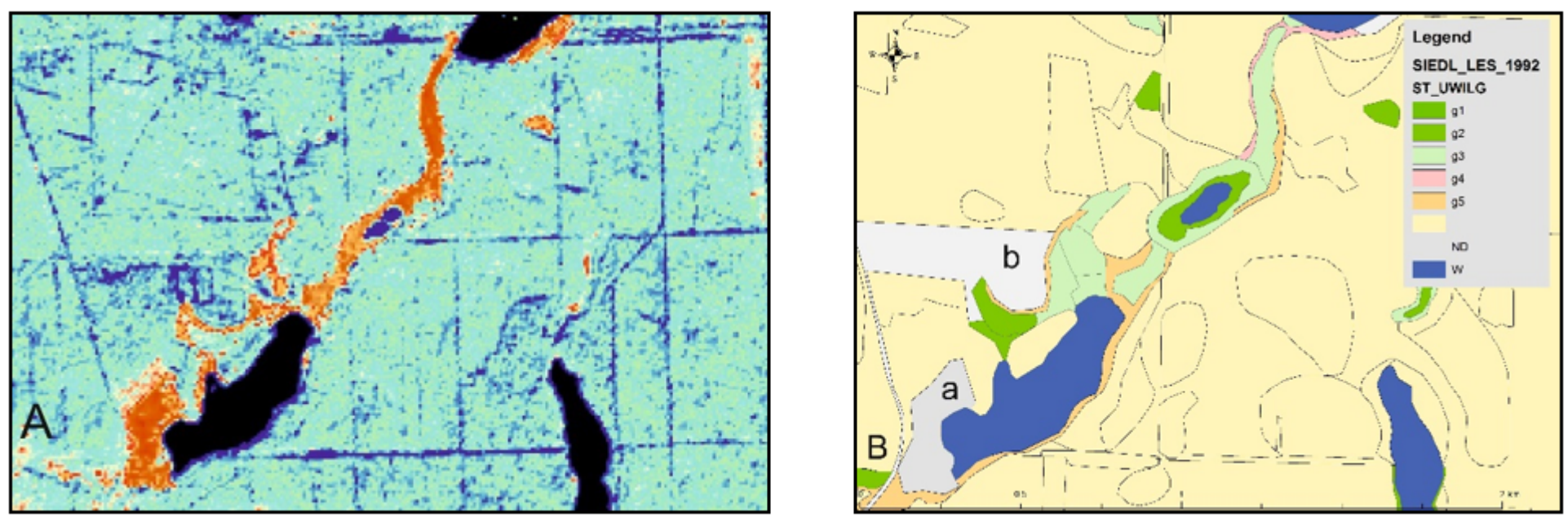

\section{Figure 34}

Compare EVI (A) with the moisture content map of BTNP (B). The letter "a" on the B map means a meadow, the letter "b" the private land taken over by the Park, for which no habitat development has been carried out, hence no data on the degree of moisture content 

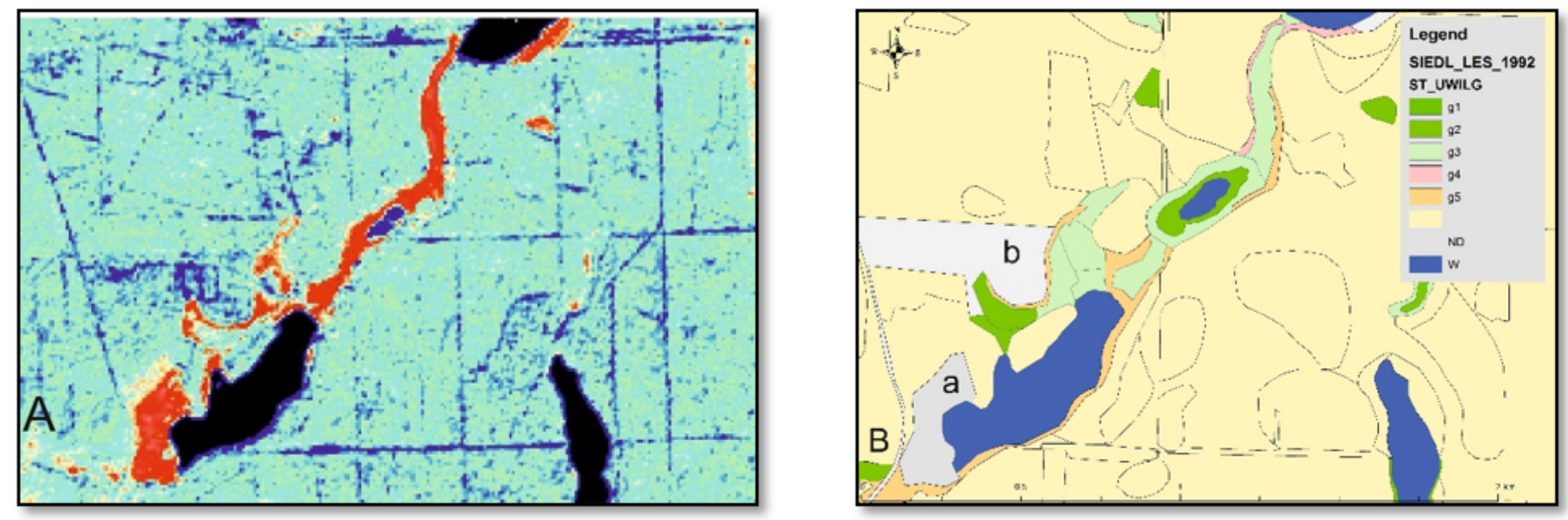

Figure 35

Compare SAVI (A) with the moisture content map of BTNP (B). The letter "a" on the B map means a meadow, the letter "b" the private land taken over by the Park, for which no habitat development has been carried out, hence no data on the degree of moisture content. FHMls g1 and g2 were combined into 1 green color
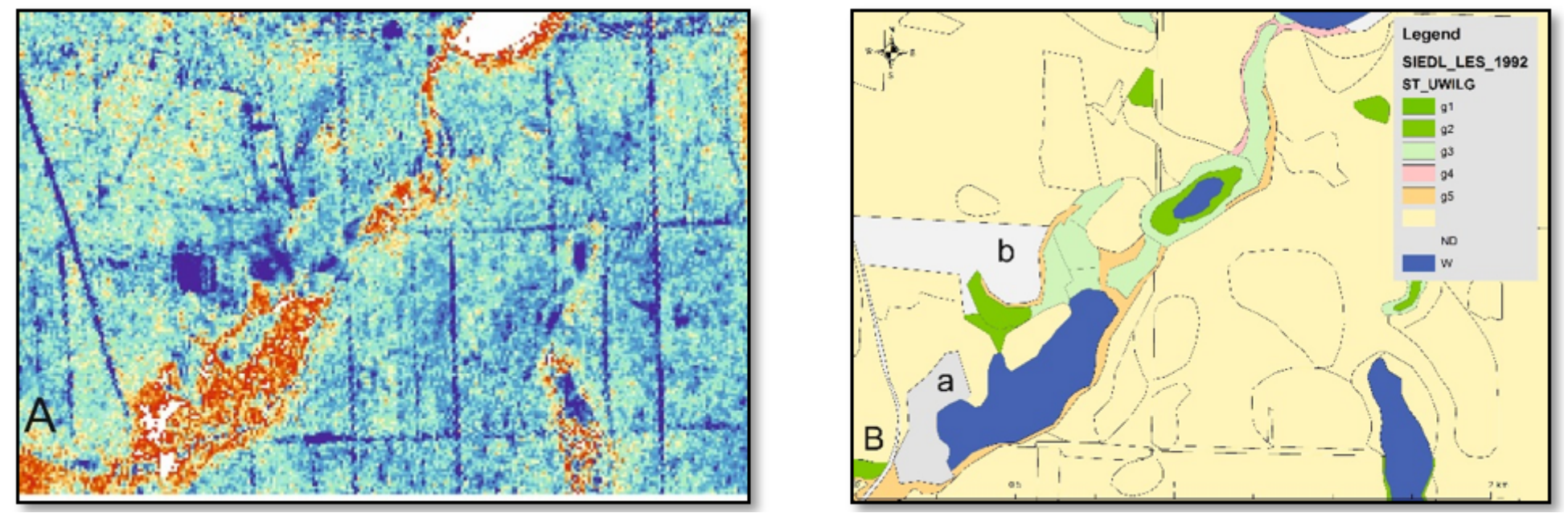

Figure 36

Compare SR520/670 (A) with the moisture content map of BTNP (B). The letter "a" on the B map means a meadow, the letter "b" the private land taken over by the Park, for which no habitat development has been carried out, hence no data on the degree of moisture content 

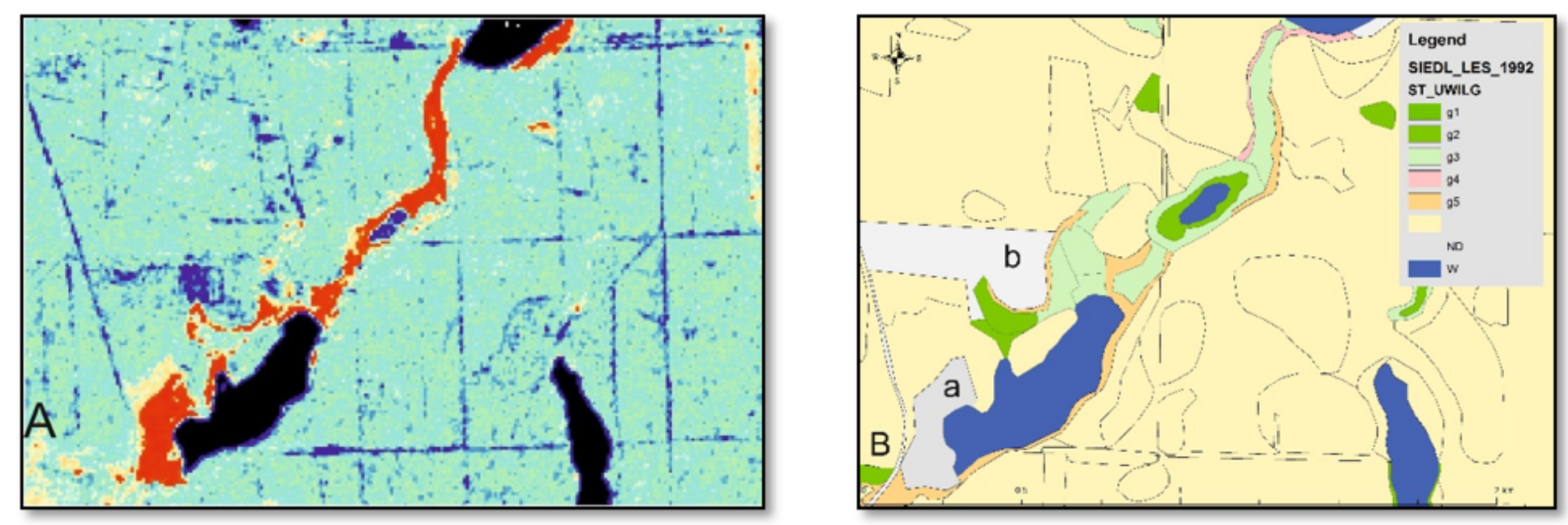

Figure 37

Compare OSAVI (A) with the moisture content map of BTNP (B). The letter "a" on the B map means a meadow, the letter "b" the private land taken over by the Park, for which no habitat development has been carried out, hence no data on the degree of moisture content 

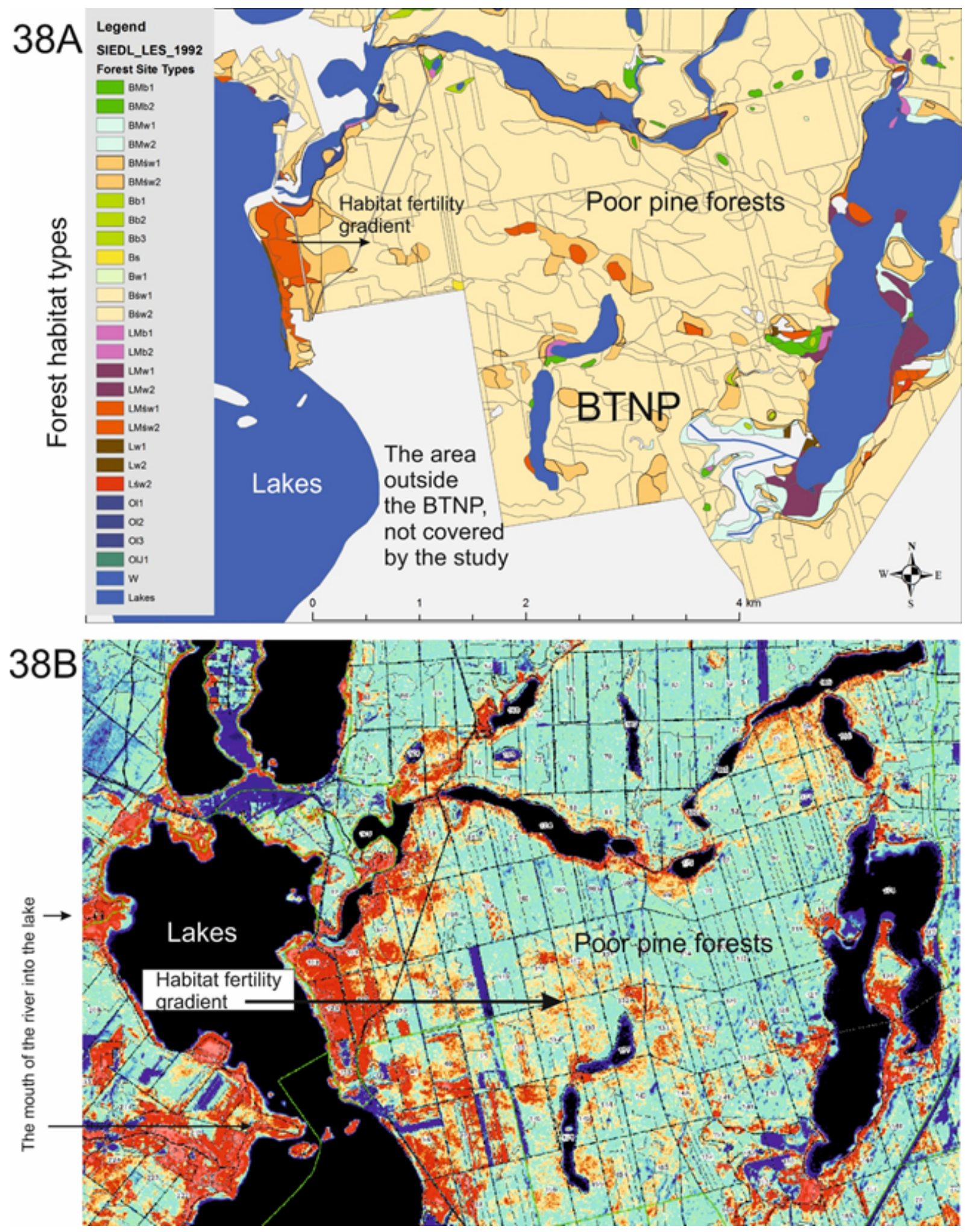

Figure 38

Differentiation of the trophic nature of forest habitats according to the map of forest habitats classified after Zielony et al. (2004) and Święcicki (2012) and prepared using the traditional method (38A) and on the basis of the NDVI index (38B) 


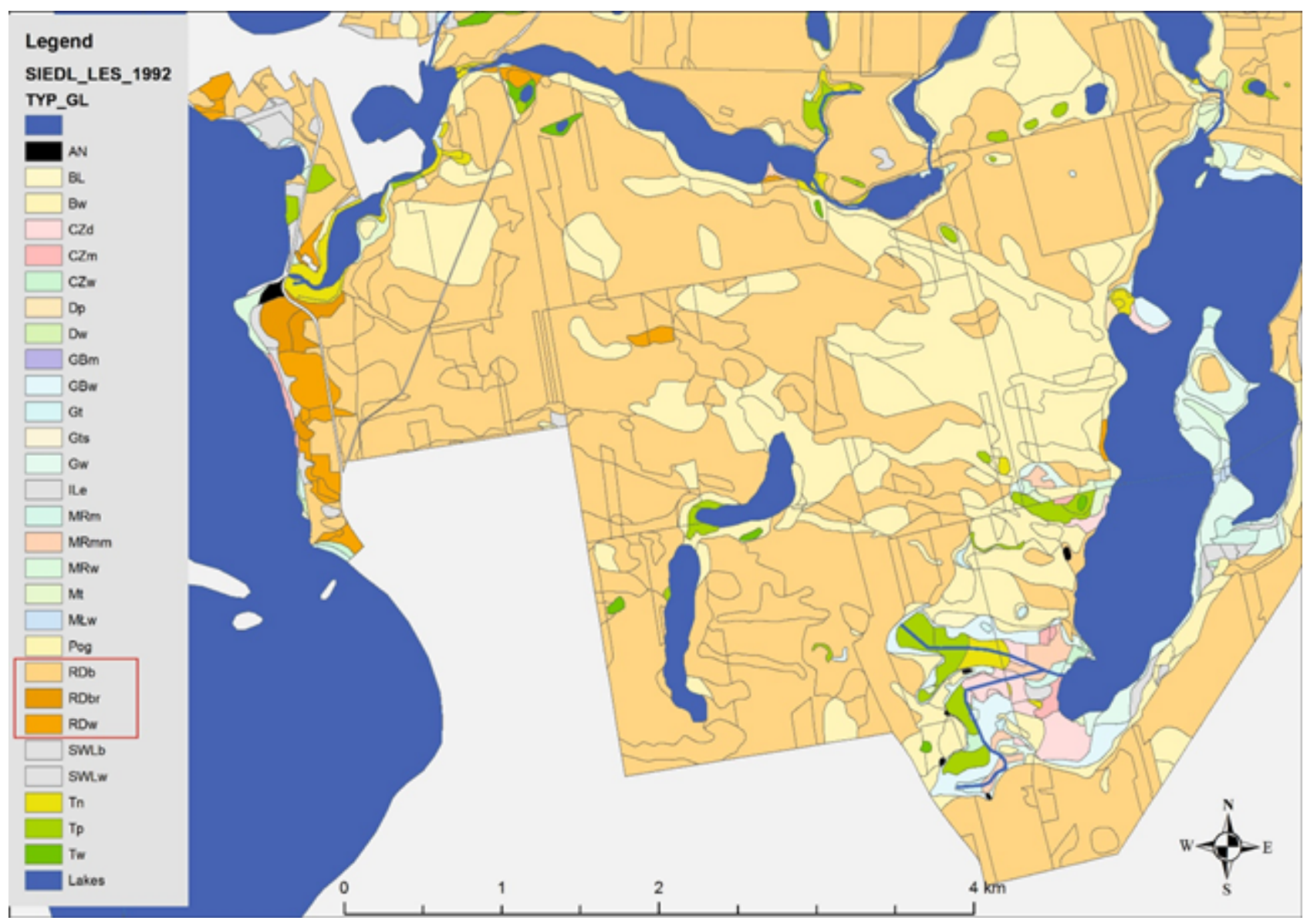

Figure 39

Classification of the soils of the selected area of the BTNP (according to http://gis.pnbt.com.pl/) on the basis of traditional soil pits. In the legend, rusty soils are marked with a red rectangle, differentiating into three subtypes: rusty podzolic (RDb), typical rusty (RDw) and brunic rusty (RDbr). Podzolic soils (BL and $\mathrm{Bw})$ also have a significant share on the map

\section{Supplementary Files}

This is a list of supplementary files associated with this preprint. Click to download.

- suplementary.zip 